\title{
Spatio-Temporal Assessment of Global Precipitation Products over the Largest Agriculture Region in Pakistan
}

\author{
Zain Nawaz ${ }^{1,2} \oplus$, Xin $\mathrm{Li}^{3,4}\left(\mathbb{0}\right.$, Yingying Chen ${ }^{3,4, *} \mathbb{0}$, Naima Nawaz ${ }^{5}$, Rabia Gull ${ }^{6}$ \\ and Abdelrazek Elnashar ${ }^{7}$ D \\ 1 Key Laboratory of Remote Sensing of Gansu Province, Northwest Institute of Eco-Environment and \\ Resources, Chinese Academy of Sciences, Lanzhou 730000, China; zain-nawaz@lzb.ac.cn \\ 2 University of Chinese Academy of Sciences, Beijing 100049, China \\ 3 National Tibetan Plateau Data Center, Key Laboratory of Tibetan Environmental Changes and Land Surface \\ Processes, Institute of Tibetan Plateau Research, Chinese Academy of Sciences, Beijing 100101, China; \\ xinli@itpcas.ac.cn \\ 4 CAS Center for Excellence in Tibetan Plateau Earth Sciences, Beijing 100101, China \\ 5 Department of Rural Sociology, University of Agriculture, Faisalabad 38040, Pakistan; \\ naimauaf@hotmail.com \\ 6 Department of Botany, University of Agriculture, Faisalabad 38040, Pakistan; Gull.rabi@gmail.com \\ 7 State Key Laboratory of Remote Sensing, Aerospace Information Research Institute, Chinese Academy of \\ Sciences, Beijing 100094, China; abdelrazek.elnashar@cu.edu.eg \\ * Correspondence: chenyy@itpcas.ac.cn; Tel.: +86-10-84097114
}

Received: 30 September 2020; Accepted: 22 October 2020; Published: 6 November 2020

\begin{abstract}
Spatial and temporal precipitation data acquisition is highly important for hydro-meteorological applications. Gridded precipitation products (GPPs) offer an opportunity to estimate precipitation at different time and resolution. Though, the products have numerous discrepancies that need to be evaluated against in-situ records. The present study is the first of its kind to highlight the performance evaluation of gauge based (GB) and satellite based (SB) GPPs at annual, winter, and summer monsoon scale by using multiple statistical approach during the period of 1979-2017 and 2003-2017, respectively. The result revealed that the temporal magnitude of all the GPPs was different and deviate up to 100-200 $\mathrm{mm}$ with overall spatial pattern of underestimation (GB product) and overestimation (SB product) from north to south gradient. The degree of accuracy of GB products with observed precipitation decreases with the increase in the magnitude of precipitation and vice versa for SB precipitation products. Furthermore, the observed precipitation revealed the positive trend with multiple turning points during the period 1979-2005. However, the gentle increase with no obvious break point has been detected during the period of 2005-2017. The large inter-annual variability and trends slope of the reference data series were well captured by Global Precipitation Climatology Centre (GPCC) and Tropical Rainfall Measuring Mission (TRMM) products and outperformed the relative GPPs in terms of higher $R^{2}$ values of $\geq 0.90$ and lower values of estimated RME $\leq 25 \%$ at annual and summer monsoon season. However, Climate Research Unit (CRU) performed better during winter estimates as compared with in-situ records. In view of significant error and discrepancies, regional correction factors for each GPPs were introduced that can be useful for future concerned projects over the study region. The study highlights the importance of evaluation by the careful selection of potential GPPs for the future hydro-climate studies over the similar regions like Punjab Province.
\end{abstract}

Keywords: gridded precipitation products; abrupt changes; trends; statistical indicators; agriculture; Pakistan 


\section{Introduction}

Accurate and reliable estimates of global climate patterns are directly associated with the regional variation in precipitation [1]. The changes in amount and pattern of precipitation could directly influence the water resources and agriculture of the concerned regions [2]. Therefore, understanding the spatiotemporal variation in precipitation on the regional scales is of great importance in climate monitoring and in hydro-climate studies [3]. Several researchers have reported the spatiotemporal variations of precipitation for different regions of the world [4-7]. There is a growing agreement that long term changes in precipitation could alter the ecological and hydrological processes [8] and underpin our knowledge of global and regional climate change [9]. These accurate and reliable precipitation records underpin our knowledge of regional and global climate change, as well as their possible impacts on water resources $[10,11]$.

In general, gauge measurements are the basic and reliable way of precipitation data acquisition [12]. Unfortunately, scarce gauge records, irregular distribution, limited data access, and poor spatial coverage hinder their use in conducting hydro-meteorological studies and climate change assessments $[13,14]$. In recent decades, with the advancement in remote sensing and geo-information technology, the gridded precipitation products (hereafter GPPs) has proven to be a reliable and cost-effective way of retrieving gridded precipitation data at various spatial and temporal scales across the globe [15]. These precipitation data either derived from satellite products or from the nationwide meteorological stations by using different interpolated algorithms and computational techniques by considering the physical characteristics (slope and elevation) of different regions. These multi-source data products are often applied as climatological input for hydro-climate simulation studies in data scarce extents to bridge the gap at regional scale [16] and there has been a considerable increase in the use of these products, owing to their easy accessibility, spatiotemporal coverage, and fine resolutions [17].

The evaluation of GPPs has also proved useful for different hydro-climate applications. The precipitation variability in different Gridded Data Products (GDPs) has been quantified for different regions across the globe [18-20]. Various studies were carried out in recent years to assess the performance of GDPs, revealing considerable differences between the products at the regional scale [21]. Furthermore, there are uncertainties that are associated with GPPs, because of the variability in spatial and temporal coverage, lack of in-situ observations, relocation of gauges, and data processing practices [22]. Thus, the reliability and accuracy of GPPs varies with time and regional climate [23]. Therefore, it is highly important to assess and evaluate the performance and capability of the GPPs at regional scales, especially the arid and semi-arid regions that are more sensitive to insignificant changes in climatic characteristics due to its fragile ecosystems [24]. Such regions are characterized by very complex hydrological systems that often exhibit extreme behaviors, such as extended droughts due to prolonged dry spell and floods due to high-intensity precipitation [25]. The predominantly arid and semi-arid climate and geographical location in the fast temperature rising region have made Pakistan one of the most vulnerable countries in the world to climate change [1]. Moreover, the natives of the country are mostly engaged in agriculture, a highly susceptible sector to climate change, with limited resources to adapt to changing circumstances [26].

Few studies were carried out in order to evaluate the performance of different GPPs against the reference data, which mainly focused on the basin level or higher altitude sites of the country and ignored the important segment of spatiotemporal precipitation variations in agricultural region of the country. For instance, [27] assessed the precipitation distribution in the high altitude region of Hindu-Kush-Himalaya basins by using different precipitation products. The study reported the better performance of ECMWF Re-Analysis (ERA-Interim) product at high catchments as compared with WATCH Forcing Data Methodology (WFDEI) and APHRODITE products. Using different gridded precipitation products, $[28,29]$ reported the significant errors in different gridded product; however, Tropical Rainfall Measuring Mission (TRMM) Multi-satellite Precipitation Analysis (TMPA) product performed better in the high catchments of the Indus basin. On the contrary, [30] reported 
the overestimation of TMPA products against reference data using the simple statistical metric approach over the complex topography of Pakistan. The present study is first of its kind, which aims to bridge the gap of knowledge with a detailed multiple-scale assessment of the spatiotemporal uncertainties of selected global precipitation products that are generated by different sources by using different statistical metrics, trends evaluation and comparison approach over the Punjab province, Pakistan. It is worth mentioning that Punjab province is highly important in the perspective of agriculture and irrigated farming as it produces major agriculture commodities of the country and it is highly vulnerable to changes in most of meteorological parameters with high frequency events and, hence. is highly prone to climate change [31]. In this study, we aim to assess the quality and differences of the different GPPs generated from multiple sources, i.e., Gauge Based (GB) products, Global Precipitation Climatology Centre (GPCC), Center for Climatic Research, University of Delaware (UDel), Asian Precipitation-Highly-Resolved Observational Data Integration Towards Evaluation (APHRODITE), Climate Prediction Centre (CPC), Climatic Research Unit, University of East Angelia (CRU) and Satellite Based (SB) products, Tropical Rainfall Measuring Mission (TRMM, Precipitation Estimation from Remotely Sensed Information using Artificial Neural Networks-Climate Data Record (PERSIANN-CDR), Precipitation Estimation from Remotely Sensed Information using Artificial Neural Networks- Cloud Classification System (PERSIANN-CCS), Global Satellite Mapping of Precipitation (GSMap) and Climate Hazard Group Infrared Precipitation with Station Data(CHIRPS) during the period of 1979-2017 and 2003-2017, respectively, over the Punjab province in Pakistan. Secondly, to evaluate and compare the changes in temporal trends and abrupt turning points in selected GPPs against the reference data for the study region. We perceive the usefulness of this study as multi-directional, because the findings of the study could be used as baseline for the selection of potential GB and SB GPPs over multiple time scales for different hydro-meteorological studies.

\section{Study Area}

Pakistan is geographically located in southwest Asia with an area of $8 \times 10^{6} \mathrm{~km}^{2}$ between latitude and longitude range of $24-37^{\circ} \mathrm{N}$ and $60-75^{\circ} \mathrm{E}$ (Figure 1). The country has diverse topography that ranges from Karakoram and Himalayan mountains in the north and northwest to the agriculture plains in the center and south of the Indus basin along the southern cost of the Arabian sea [32]. Pakistan is an agrarian country and Punjab is the second largest Province with geographical coordinates of $31.17^{\circ} \mathrm{N}$ and $72.70^{\circ} \mathrm{E}$. The Province has the largest population and producing more than $50 \%$ of the country's agricultural commodities [33]. The regional mean temperature varies from 23 to $26^{\circ} \mathrm{C}$, with a $\mathrm{T}_{\min }$ of $16-19{ }^{\circ} \mathrm{C}$ and a $\mathrm{T}_{\max }$ of $29-33^{\circ} \mathrm{C}$. The northern part of the Province receiving more precipitation than southern part with overall annual mean precipitation ranges from $<300 \mathrm{~mm}$ in the southern part to $>800 \mathrm{~mm}$ in the northern part [34]. The two major seasons that dominates the overall hydrology of the region, i.e., the summer monsoon (June-September) and winter monsoon seasons (December-April) [35]. The maximum precipitation occurs during the summer monsoon due to the monsoon system that originates from Bay of Bengal and enters in the country from east and northeast [35]. The winter precipitation instigates from the Mediterranean Sea due to western disturbances and enters in the country from southwest and northeast direction [35]. There is great variation and extreme events during summer and winter monsoon precipitation seasons that make this region a highly susceptible to climate change [36]. Due to highly vulnerable in precipitation changes, the spatial and temporal evaluation of the GPPs is highly important for further application of these products, including hydro-meteorological studies over the study region. 


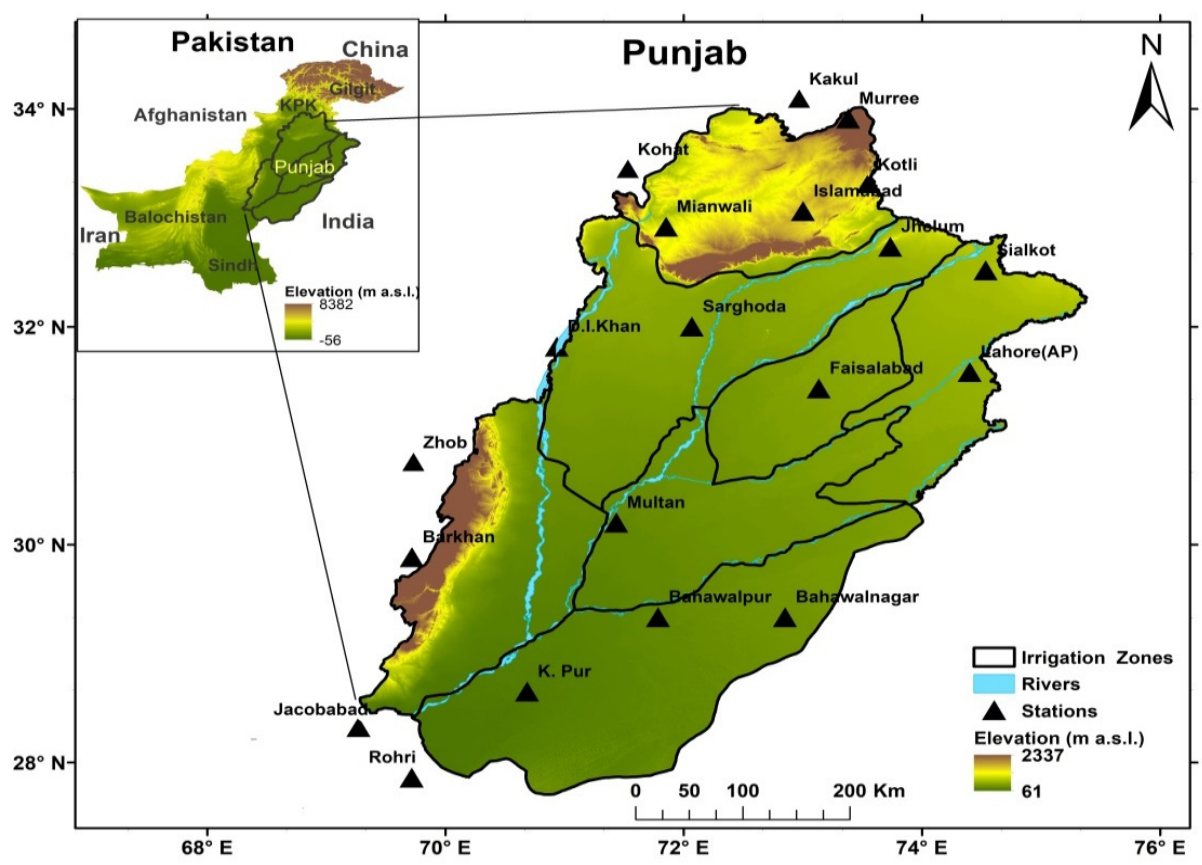

Figure 1. Study area and meteorological stations.

\section{Materials and Methods}

\subsection{In-Situ Records}

The long term monthly precipitation data that were collected from 20 meteorological stations over the Punjab region were acquired from Pakistan Meteorological Department (PMD) (Figure 1). The in-situ records were investigated during the study periods from 1979 to 2017 and from 2003 to 2017 as reference data for the assessment of GB and SB precipitation products, respectively. The selection of the gauges depends on their maximum availability and completeness of data series. The GPPs were evaluated against the in-situ records on an annual, winter, and summer monsoon season. The winter and summer monsoon seasons are the primary drivers of the annual hydrological cycle with major influence of Asian monsoon (summer monsoon season) over the study region [28]. The GB and SB GPPs were developed while using quality-controlled procedures and algorithms. However, the stations data are generally considered as standard measurements for the evaluation of GPPs [37,38]. Moreover, the standard quality-controlled procedures were adopted for the better accuracy assessment of GB and SB GPPs. For quality assurance, station data series were thoroughly checked and outliers were fixed with neighboring gauge records [39]. Gaps were filled using a time-based interpolation approach [40]. Several post-processing techniques have been developed to identify the consistency and homogeneity's in the station records [41]. The double-mass curve was applied to observe the inhomogeneity in the station records [42]. The curve of all the stations showed a straight line with no evident break points, which confirms a temporal consistency and uniformity in the time series records.

After quality control process in the reference data series, the thin-plate splines (TPS) interpolation method was introduced to convert the station data into products relative spatial grid sizes for the assessment of GB and SB GPPs on spatial scale. The original TPS method is defined by [43], whereas [44] provides a detailed description of its application for different climate indicators. The TPS scheme is applicable and robust in regions where stations density is low and prior estimation of the spatial auto-covariance is not required [44]. The time series autocorrelation method was applied prior to estimate the trend significance, magnitude, and abrupt turning point to ensure the occurrence of significant autocorrelation in the reference data series [1]. The presence of significant autocorrelation in the reference data series could influence the outcome of Mann-Kendall (MK), Sen's Slope (SS), 
and Mann-Kendall abrupt change analysis [45]. Therefore, the significance of autocorrelation should be checked before applying the trend tests [46]. The analysis revealed no significant autocorrelation in the reference data series of annual, winter, and summer monsoon seasons. Therefore, the in-situ records are completely independent, and the MK test is applicable to the original gauge records. The detailed description for autocorrelation method is reported by [47].

\subsection{Gridded Precipitation Products (GPPS)}

In this study, GB and SB GPPs (GPCC, UDel, APHRODITE, CPC, CRU, TRMM, PERSIANN-CDR, PERSIANN-CCS, and CHIRPS, GSMap) were evaluated against the reference data (Table 1). Details of the datasets are described below.

\subsubsection{Gauge-Based GPPs}

The Global Precipitation Climatology Centre (GPCC) obtained the primary data from meteorological agencies at National level (NMAs), Food and Agriculture Organization (FAO), Climate Research Unit, University of East Angelia (CRU), and Global historical climatology network (GHCN) at the National Centers for Environmental Information [48]. The product covers the period from 1891 to 2018. In this research, the monthly product of $0.5^{\circ}$ spatial resolution is used from the period 1979-2017. The product from University of Delaware, USA (UDel) acquired the primary data from GHCN2, daily GHCN from National Centers for Environmental Information, National Center Atmospheric Research (NCAR), Project Greenland of automatic meteorological stations, Data archives of Nicholson for African continent, records of daily summary at the global level [49]. The product covers the period from 1900 to 2017 . The monthly precipitation data of $0.5^{\circ}$ spatial resolution from the period 1979-2017 is utilized in the study. The monthly product Climate Research Unit (CRU) acquired the primary data from the World Meteorological Organization (WMO), Food and Agriculture Organization (FAO), and National meteorological departments. The CRU product covers the period from 1901 to 2019 . The monthly precipitation data of $0.5^{\circ}$ spatial resolution from the period 1979-2017 is used in the present study [50].

The daily Asian Precipitation-Highly Resolved Observational Data Integration towards Evaluation of Water Resources (APHRODITE) product that was obtained the primary source data from multiple Asian agencies including Global Telecommunication System (GTS), National weather agencies, International Centre for Integrated Mountain Development (ICIMOD), International Water Management Institute (IWMI) and other national and international projects on climate [51]. The product covers the period from 1961 to 2015 . The daily precipitation product of $0.5^{\circ}$ spatial resolution was accumulated into monthly time scale from the period 1979-2015 in the present study. The CPC is the first product of Unified Precipitation Project at the National Oceanic and Atmospheric Administration (NOAA). The product acquired the primary data from National weather agencies, quality controlled station data from GTS, and Cooperative Observer Network [52]. The CPC product covers the period from 1948 to 2018. The daily precipitation product of $0.5^{\circ}$ spatial resolution was accumulated into monthly time scale from the period 1979-2017 in the present study.

\subsubsection{Satellite-Based GPPs}

The TRMM satellite provides the continuous precipitation data (1998-present) which covers the range from $50^{\circ} \mathrm{N}$ to $50^{\circ} \mathrm{S}$ over tropical to subtropical regions at $0.25^{\circ}$ spatial resolution [53]. The TRMM Multi-satellite Precipitation Analysis (TMPA) used three basic instruments to record the data, including Visible Infrared Scanner, Microwave Image and Radar Precipitation [30]. The TMPA provides real time and post real time products. The post real time version 7 products have adjusted with gauge data and proved higher accuracy than TMPA real time product [54]. The present study utilized the higher accurate version 7 products with monthly temporal and $0.25^{\circ} \times 0.25^{\circ}$ spatial resolution during the study period 2003-2017. 
The Precipitation Estimation from Remotely Sensed Information using Artificial Neural Networks-Climate Data Record (PERSIANN-CDR) provides longer gridded data (1983-present) with spatial resolution of $0.25^{\circ} \times 0.25^{\circ}$ at the daily timescale. The PERSIANN-CDR estimates the rainfall rate from geostationary satellites by using infrared brightness temperature [55]. The stage IV radar data from the National Centers for Environmental Prediction (NCEP) is used to train the Artificial Neural Network (ANN) model. The high resolution precipitation estimates then attuned by Global Precipitation Climatology project (GPCP) for bias correction [56]. The daily data aggregated into monthly time scale for evaluation against reference data for the study period 2003-2017.

The Precipitation Estimation from Remotely Sensed Information using Artificial Neural NetworksCloud Classification System (PERSIANN-CCS) provides the gridded precipitation data (2003-present) at spatial resolution of $\left(0.04^{\circ}\right.$ and $30 \mathrm{~min}$.) by using Infrared brightness temperature derived from geostationary satellites and continuously updating its parameter using Passive Microwave (PMW) measurements from low earth orbit satellites. The regression and histogram matching are used to draw fit curve plot between temperature brightness of pixel and rainfall rate to achieve rainfall mapping of each classified cloud cluster [57]. The daily data aggregated into monthly time scale for evaluation against reference data for the current study period 2003-2017. The CHIRPS precipitation dataset is quasi land product belongs to Climate Hazard Group with a spatial resolution of $0.05^{\circ} \mathrm{s}$ and temporal daily scale derived from TRMM satellite, and several observed products such as NOAA, CPC, National Climatic Data Center (NCDC) and Climate Forecast System version 2 (CFSv2). The product algorithm is based on the concept of cold cloud duration (CCD), which is the duration of time of pixel covered by IR brightness temperature. Precipitation estimates by using CCDs procedure by incorporating TMPA3B42 product and merged with observed measurements using the Inverse Distance Weighting (IDW) method to produce final product [58]. For the current study, the daily data aggregated into monthly time scale during the study period 2003-2017. The recent GSMap project is launched by Japan Aerospace Exploration Agency (JAXA) to monitor precipitation at higher spatial resolution of $0.1^{\circ}$ and one-hour temporal scale. The product input is based on multiple polar orbiting satellites with adjusted accuracy of Kalman smoothing approach [59]. The product covers the range of latitude and longitude from $60^{\circ} \mathrm{N}$ to $60^{\circ} \mathrm{S}$ and from $180^{\circ} \mathrm{W}$ to $180^{\circ} \mathrm{E}$, respectively. For the present study, the hourly data converted into monthly time series during the period 2003-2017.

Table 1. Information of gauge based (GB) and satellite based gridded data products (SB GPPs) used in the study.

\begin{tabular}{cccccc}
\hline Datasets & Resolution & Frequency & Coverage & Study Period & Reference \\
\hline APHRODITE & $0.5^{\circ}$ & Monthly & Global land & $1979-2015$ & {$[51]$} \\
CRU & $0.5^{\circ}$ & Monthly & Global land & $1979-2015$ & {$[50]$} \\
CPC & $0.5^{\circ}$ & Monthly & Global land & $1979-2015$ & {$[52]$} \\
GPCC & $0.5^{\circ}$ & Monthly & Global land & $1979-2013$ & {$[48]$} \\
UDel & $0.5^{\circ}$ & Monthly & Global land & $1979-2015$ & {$[49]$} \\
TRMM & $0.25^{\circ}$ & Monthly & Global land & $2003-2017$ & {$[53]$} \\
GSMap & $0.1^{\circ}$ & Monthly & Global land & $2003-2017$ & {$[59]$} \\
CHIRPS & $0.05^{\circ}$ & Monthly & Global land & $2003-2017$ & {$[58]$} \\
PERSIANN-CDR & $0.25^{\circ}$ & Monthly & Global land & $2003-2017$ & {$[55]$} \\
PERSIANN-CCS & $0.04^{\circ}$ & Monthly & Global land & $2003-2017$ & {$[57]$} \\
\hline
\end{tabular}

\subsection{Descriptive Methods}

Here, we assess the spatial and temporal performance of each GPP against the in-situ records using different statistical techniques. The quantitative statistical indicators, including the root mean square error (RMSE), Pearson correlation coefficient (CC), and standard deviation were applied while using a Taylor diagram, which is a precise technique of measuring the degree of accuracy between GPPs and reference data [60]. The mean error (ME) and relative mean error (RME) were calculated in order to indicate the systematic bias which determines the level of over-or under-estimation of 
GPPs against in-situ data. Furthermore, the scatter plots were also used to determine the quantitative linear relationship between each GPP against the reference data. Furthermore, the detection and comparison of trends in different GPPs data series were evaluated against the reference data using the non-parametric Mann-Kendall (MK) test. The MK trend test is simple and it has been widely used for the detection of significant trends in hydro-meteorological time series data [61,62]. The trend test is robust against normal distribution, missing values, outliers and is less susceptible to the abrupt change point [63].

Similarly, the Theil and Sen's Slope (TSS) is non-parametric test, which can be used to quantify the slope magnitude in linear trends [64]. The TSS has been widely acceptable and used by many researchers to detect the significant trends in different climate indicators [19]. The test is based on least square regression technique, which is commonly used to estimate the rate of slope in a given time series data $[65,66]$. Moreover, the abrupt change analysis was performed using the Sequential Mann Kendall (SQMK) test. The SQMK test was proposed by [67] and it has been widely used to identify the abrupt change point in hydro-meteorological time series data [49]. The test sets up two temporal series based on forward and backward process i.e., progressive series (PS) and retrograde series (RS). In this test, the progressive series is a standardized variable with zero mean and unit standard deviation. The nature of the progressive series is same as that of $Z$ values, which range from the initial to last data point. Similarly, the value of the retrograde series is computed backwards, starting from the end point and finishing at the first point of the temporal series. The positive and negative change in time series data indicate increasing and decreasing trends, respectively [67]. Details of the descriptive statistical methods are discussed and reported by many research papers [68-71]

\section{Results}

\subsection{Evaluation of Temporal and Spatial Dynamics}

Annual and Seasonal Scale

The annual averages of precipitation, as estimated from reference and gridded data products (GPPs) over Punjab region, are shown in Figure 2. The temporal trends indicated that the annual precipitation amounts that were underestimated by the GPPs with the exception of TRMM and PERSIANN-CDR products, which overestimated the magnitude as compared with the reference data. The temporal magnitude in all the precipitation products was different and deviate up to 100-200 mm as compared with in-situ measurements. However, the most identical temporal fluctuation pattern of precipitation was observed in GPCC and TRMM products with the relative mean error of $-16.59 \%$ and $2.88 \%$, respectively. Figure 3 illustrates the spatial distribution of GPPs and observed annual average precipitation. The results indicated that, the spatial configuration of GPPs exhibited the similar pattern of precipitation as compared with observed estimates. Across all of the GPPs, the northern part of study area received more amount of precipitation than southern part and exhibited the precipitation pattern towards south to north gradient with the range of 15-1500 mm. In all GPPs, the spatial consistency was observed with a major deviation in northern Punjab. However, the most accurate and consistent spatial pattern was observed in GPCC and TRMM product and the lowest spatial accuracy was observed in CPC following by UDel and PERSIANN-CCS products particularly in northern Punjab. These products were relatively less accurate to capture the higher amount of precipitation distribution over the northern part of the study region. In contrast, the APHRODITE product showed less precipitation magnitude in the central and southern Punjab as compared with observed precipitation. The spatial distribution of the APHRODITE product showed better results at high catchments of the study region as compared with plain areas. These results are consistent with the findings of [27], who reported the better performance of APHRODITE product as compared with reference data at high-altitude catchments in Pakistan. 


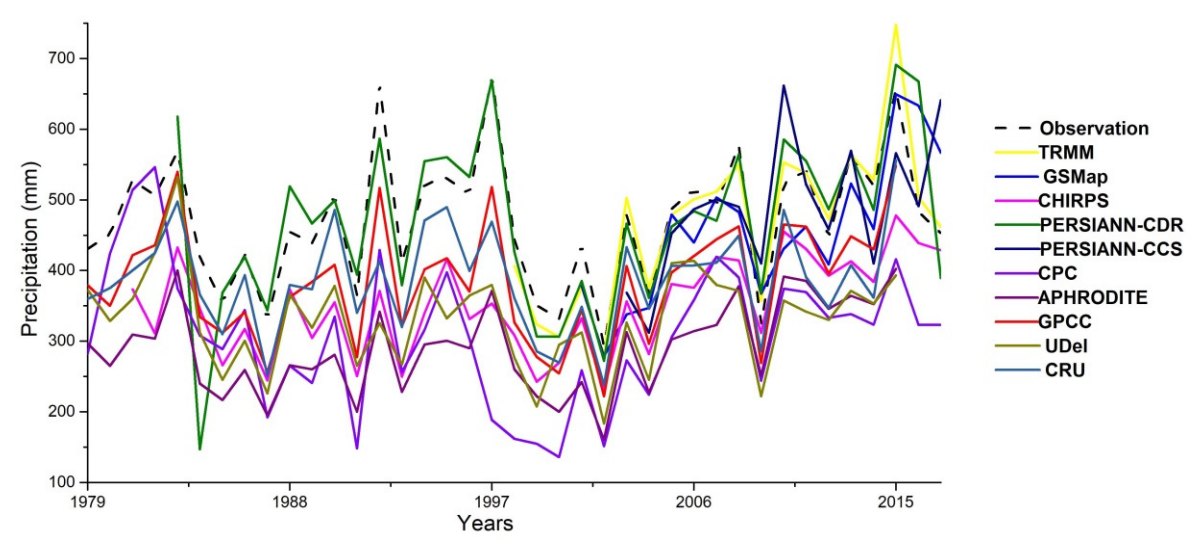

Figure 2. Mean annual variation in GPPs and reference data.

$\mathbf{A}$

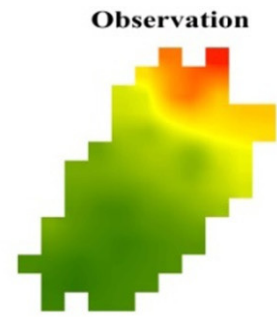

APHRODITE

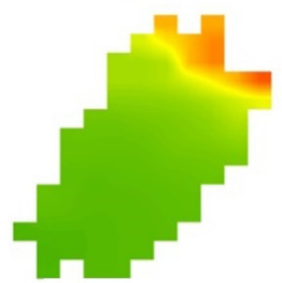

B

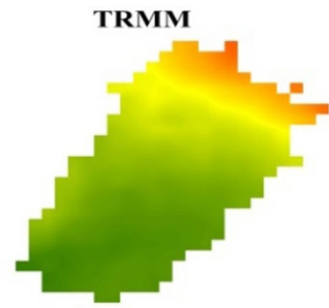

CHIRPS

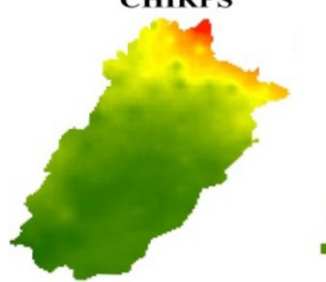

\begin{tabular}{lllll}
0 & $100200 \quad 400 \quad 600 \quad 800$ \\
\hline
\end{tabular}
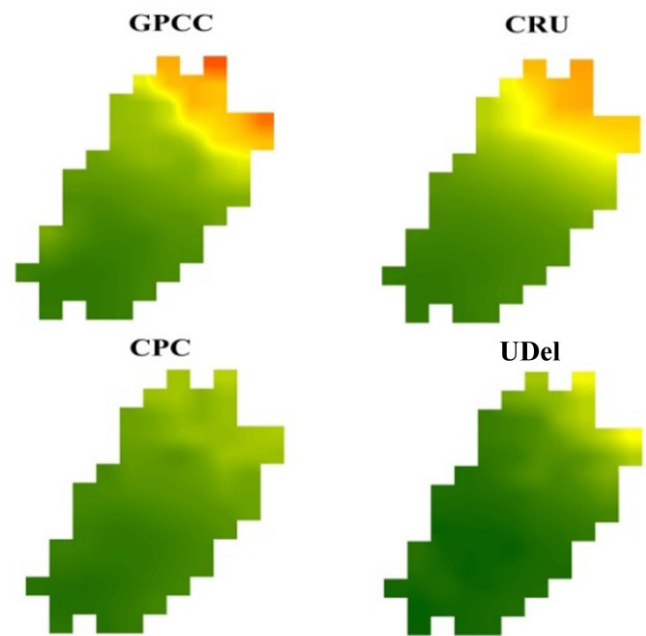

$\mathrm{N}$

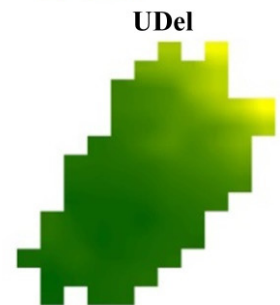

GSMap

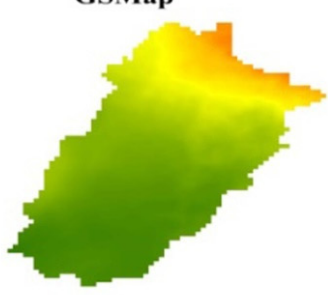

PERSIANN-CDR

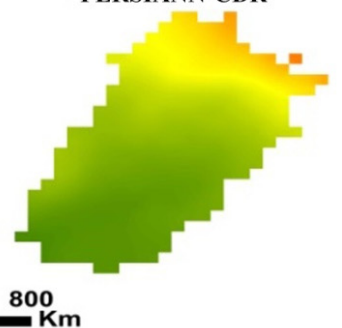

PERSIANN-CCS

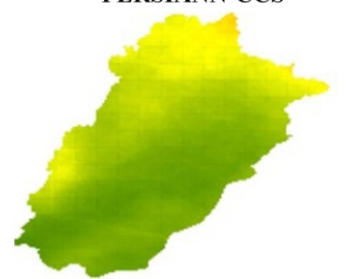

High : 1500

Low : 15
Precipitation $(\mathbf{m m})$

Figure 3. Spatial distribution of annual average of (A) GB and (B) SB precipitation products during the whole study periods.

The descriptive statistical measures divulge the characteristics of GPPs when compared with the reference data. Figures 4-6 indicates the plots as A (GB) and B (SB) precipitation products against the reference data during annual, winter, and summer monsoon, respectively. The result showed that, all the selected GPPs underestimated the annual precipitation amount, except TRMM and PERSIANN-CDR 
product, which indicates the overestimation of precipitation over the study region. The highest accuracy was observed in the GPCC and TRMM products with lowest mean error and higher R-squared value with the magnitude of $-76.35(0.90)$ and $14.26 \mathrm{~mm}(0.90)$ respectively. These products are comparatively better to capture the annual precipitation variability over the study region. However, the lowest accuracy was observed in CPC and PERSIANN-CCS products with the magnitude of mean error -163.57 $(-34.71 \%)$ and $-16.08 \mathrm{~mm}(-3.23 \%)$, respectively. These datasets are relatively less accurate for capturing the annual variability amount of precipitation during the whole study period. Moreover, the GSMap and PERSIANN-CCS products overestimated the precipitation magnitude $\leq 500 \mathrm{~mm}$ and underestimated the precipitation amounts, which are $\geq 500 \mathrm{~mm}$. The inter-comparison of gridded products indicated a similar consistency, except TRMM and PERSIANN-CDR products, which showed positive bias. The underestimation was more conspicuous in GB products as compared with SB products. The SB products showed lower bias and higher accuracy as compared with GB products, which could be due to higher pixel resolution of SB products over the study region [28]. Overall, TRMM product indicated better quantitative performance and showed reasonable consistency against reference precipitation over the study region.
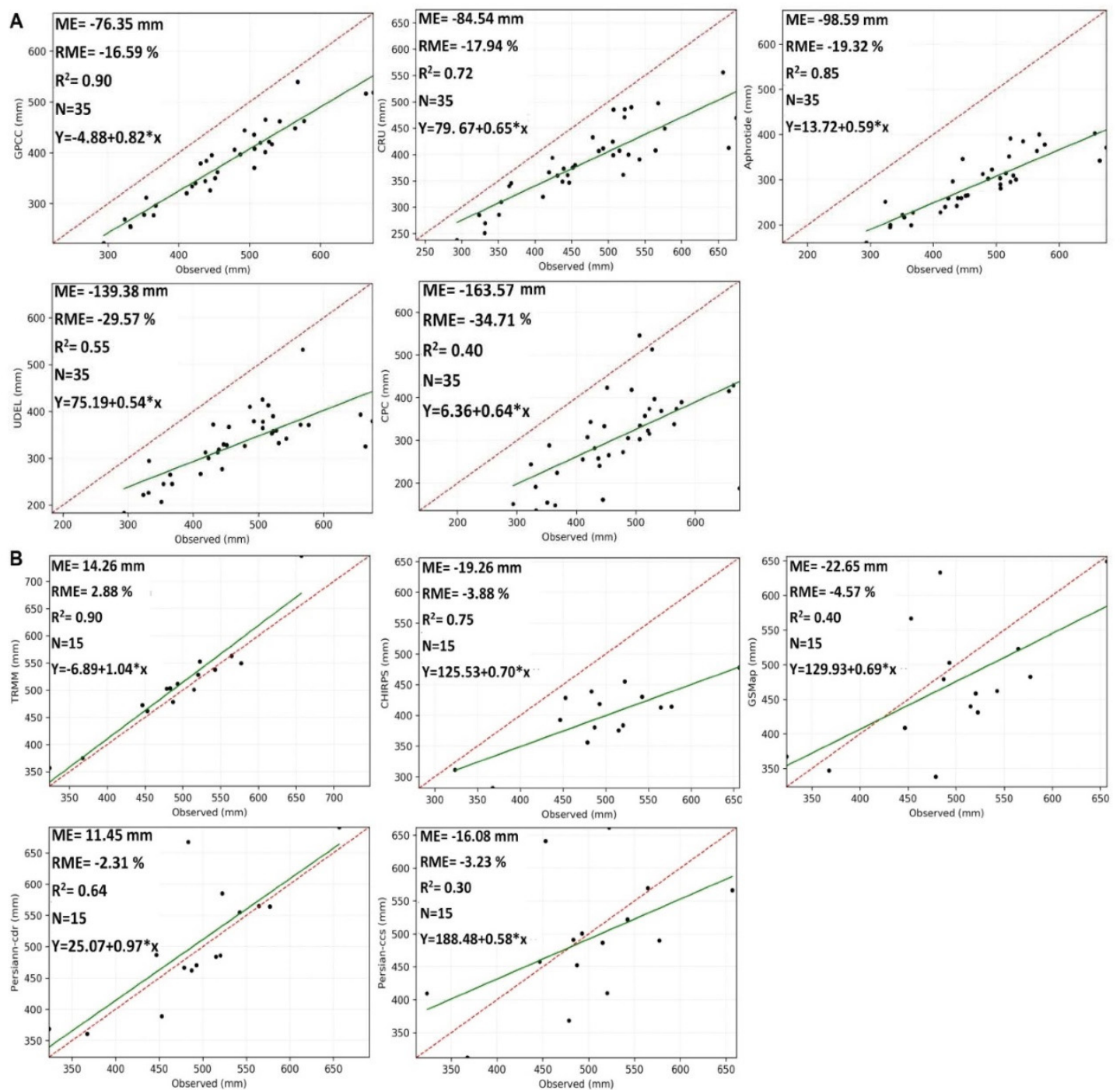

Figure 4. Statistical indicators for the assessment of (A) (GB) and (B) (SB) precipitation products against reference data (Annual timescale). 
The GB and SB precipitation products were further evaluated during winter monsoon season. All of the GB products underestimated the winter precipitation with the highest and lowest accuracy being observed in CRU and CPC product with the estimated mean error of $-25.08(-20.49 \%)$ and $37.99 \mathrm{~mm}(-31.04 \%)$, respectively. In contrast, the SB products overestimated the precipitation magnitude except CHIRPS product, which indicates the underestimation of precipitation amount over the study region. The highest and lowest accuracy was observed in TRMM and GSMap products with the estimated mean error of $24.06(19.39 \%)$ and $80.66 \mathrm{~mm}(65.03 \%)$ respectively. The rest of the precipitation products also showed better quantitative agreement with a higher range of deviation from the mean observed precipitation. Overall, the performance of CRU and TRMM were consistent and show relatively less error during the winter monsoon season.
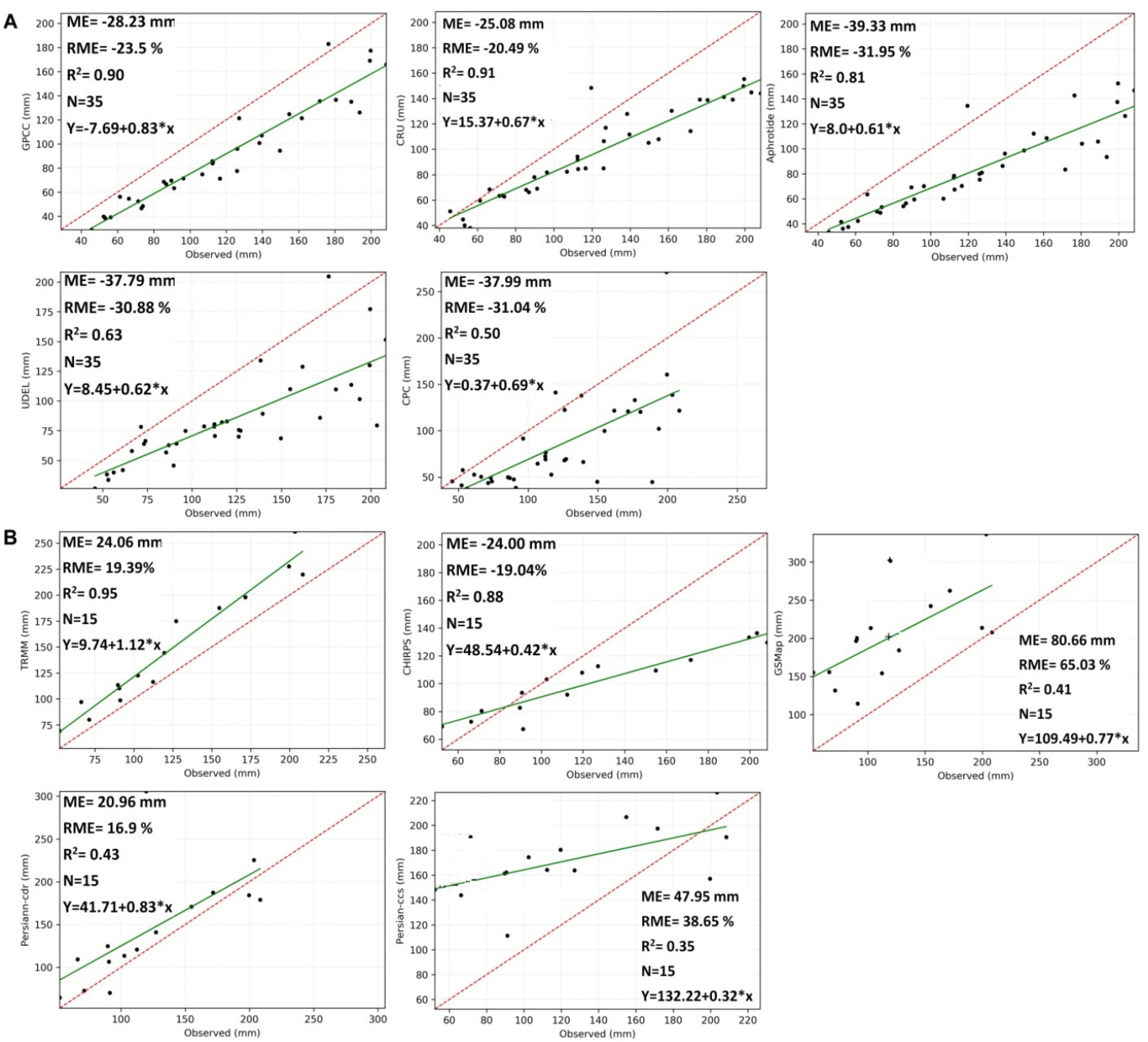

Figure 5. Statistical indicators for the assessment of (A) (GB) and (B) (SB) precipitation products against reference data (winter monsoon).

Furthermore, the evaluation of precipitation products during the summer monsoon season indicated the similar pattern of statistical metrics as assessed during annual time scale. The summer monsoon precipitation dominated the regional water balance and plays a significant role in annual precipitation variability. All of the GB and SB products underestimated the observed precipitation. The highest and lowest accuracy in GB products was observed in GPCC and CPC with the estimated mean error of $-50.03(-16.17 \%)$ and $-114.50(-36.48 \%)$, respectively. Moreover, the TRMM and GSMap showed the highest and lowest accuracy as compared with in-situ with the estimated mean error of $-15.18(-4.48 \%)$ and $-136.06 \mathrm{~mm}(-40.16 \%)$, respectively. The products underestimation was more 
conspicuous during winter monsoon period as compared with annual and summer monsoon season. Moreover, all of the SB products showed less range of mean error during annual scale following by summer and winter monsoon seasons. However, the GB products exhibited lower mean error in winter following by annual and summer scale. Overall, the performance of GPCC and TRMM products showed the best agreement with in-situ in terms of higher $R^{2}$ values of $\geq 0.90$ and lower values of $\mathrm{RME} \leq 25 \%$ during annual, winter, and summer monsoon seasons.
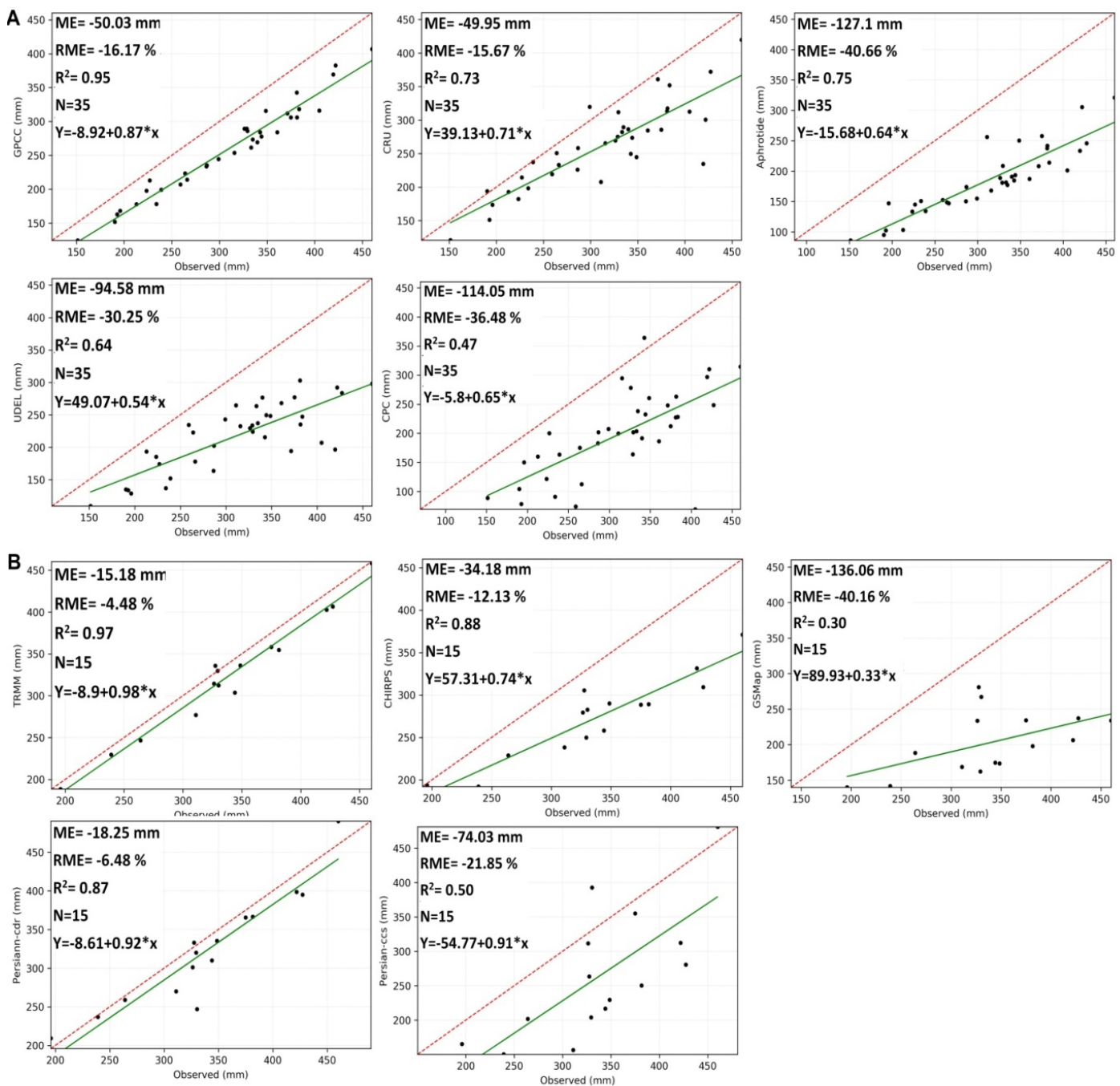

Figure 6. Statistical indicators for the assessment of (A) (GB) and (B) (SB) precipitation products against reference data (summer monsoon).

In order to evaluate the temporal pattern variability of different GPPs against observation data, Taylor diagrams were plotted [62] to quantify the precise agreement between the observation and GPPs in terms of correlation coefficients (CC), standard deviation (SD), and root mean square deviation (RMSD), which are shown in Figure 7 as A (GB) and B (SB) precipitation products during annual, winter, and summer seasons. In the diagram, correlation coefficient (CC) is denoted by blue lines adjoining perpendicular to the parabolic scale, standard deviation (SD) is denoted by radii of the black cycles and root mean square deviation (RMSD) donated by the radii of the green cycles. In the diagram, if the value of the GPPs is closer to the observation data, then it is considered to be a better product. The diagram statistics provide the evaluation of the temporal pattern of the GPPs against observed data. 

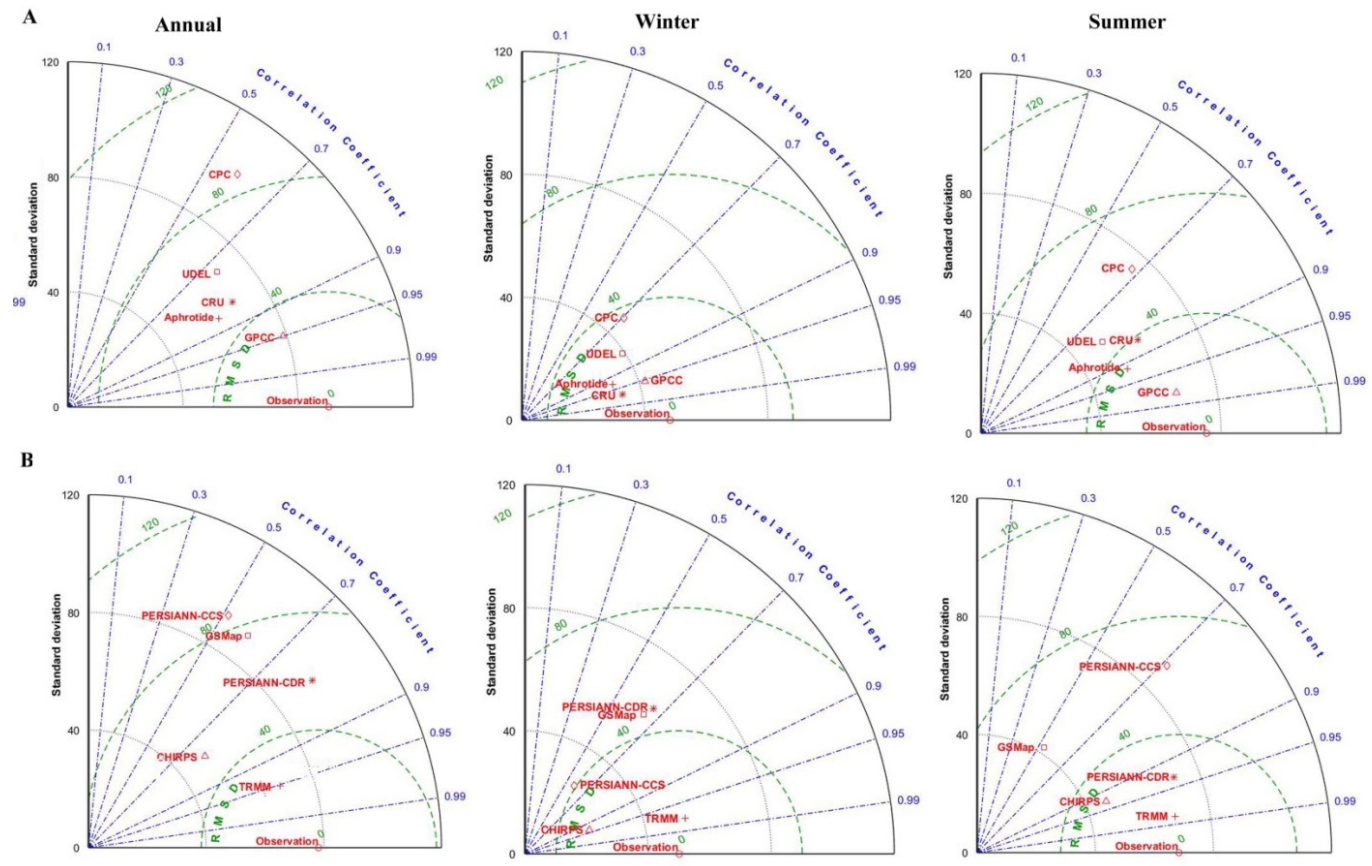

Figure 7. Statistical evaluation of (A) (GB) and (B) (SB) precipitation products against reference data by using Taylor diagram.

The results indicated that the GPCC and TRMM precipitation products outperformed the other products during the annual scale in terms of higher CC of around $95 \%$ and less value of the RMSD. The GPCC and TRMM points marked closer to the reference point indicated that the products relatively performed better and they are suitable for the study region. The rest of the precipitation products also depicted good agreement with observed data over the study region, with notable mean error all the way. These results are in agreement with the findings of $[27,72]$ who reported the better performances of TRMM and GPCC products. The range of agreement is different, which could be due to a difference in region, study period and statistical metrics. Moreover, the Taylor analysis during winter precipitation indicated the better performance of CRU and TRMM products as marked closer to the reference data with relatively higher CC of around $97 \%$ and lower values of RMSD. The GPCC, APHRODITE, and CHIRPS products also showed better efficiency in terms of high CC and lower RMSD values. On the other hand, the evaluation of precipitation products during summer monsoon revealed the better performance of GPCC and TRMM products, as indicated by a higher CC of around $98 \%$ and lower RMSD values. These results are consistent with the outcomes of products evaluation during the annual time scale over the study region. The efficiency of GPCC and TRMM precipitation products during annual and summer season was found to be similar and consistent. The major influence of annual precipitation variability depends upon the summer monsoon season, as it receives the major amount of precipitation and main driver of annual hydrological cycle [73]. Overall, the performance of GPCC and TRMM products were best during the annual and summer time scale over the study region. However, CRU product shows relatively better performance during the winter monsoon period.

Figure 8 shows the spatial distribution of GB and SB precipitation products against reference data in terms of spatial pattern of statistical indices (ME, RMSD and CC) over the Punjab region during the whole study periods. The results indicated that all of the GB products underestimated the precipitation amounts as compared with observed precipitation. The range of deviation was more conspicuous in northern Punjab with the dominated pattern of underestimation from north to south gradient. In the entire study period, the GPCC product exhibited best agreement, as indicated by the distribution of higher CC and lower values of ME and RMSD. However, the accuracy of GPCC product was more precise over northeast and southern part of Punjab. The inter-comparison of GB products indicated the similar pattern of underestimation, except the UDel and CPC product, which indicated the higher 
range of underestimation over the whole study region. Both of the products showed the lowest agreement following by APHRODITE product as compared with the observed pattern of precipitation. On the other hand, the SB precipitation products showed the visible pattern of overestimation over the whole study region. However, the pattern was more conspicuous over the northern and eastern part of the study region. Moreover, all of the products showed a similar pattern of underestimation over south-west part of the study region. However, the pattern of underestimation was more noticeable in PERSIANN products over south to south west gradient as compared with observed precipitation. The statistical pattern of all the SB products pointed out the better performance of TRMM product in terms of higher CC and lower ME and RMSD values. The TRMM product outperformed the rest of the product by showing the lowest error and highest accuracy. However, the pattern of overestimation was more noticeable over the northern region of the study area. The overestimation in these areas could be related to the higher rate of evaporation. These results are consistent with the findings of [27], who reported the higher overestimation of satellite products in the foothills of northern mountain range of Hindukush, Karakoram and Himalaya (HKH in Pakistan. Generally, the GPCC and TRMM products showed the better accuracy and consistency in terms of spatial distribution of statistical metrics with higher values of CC and lower values of ME and RMSD.

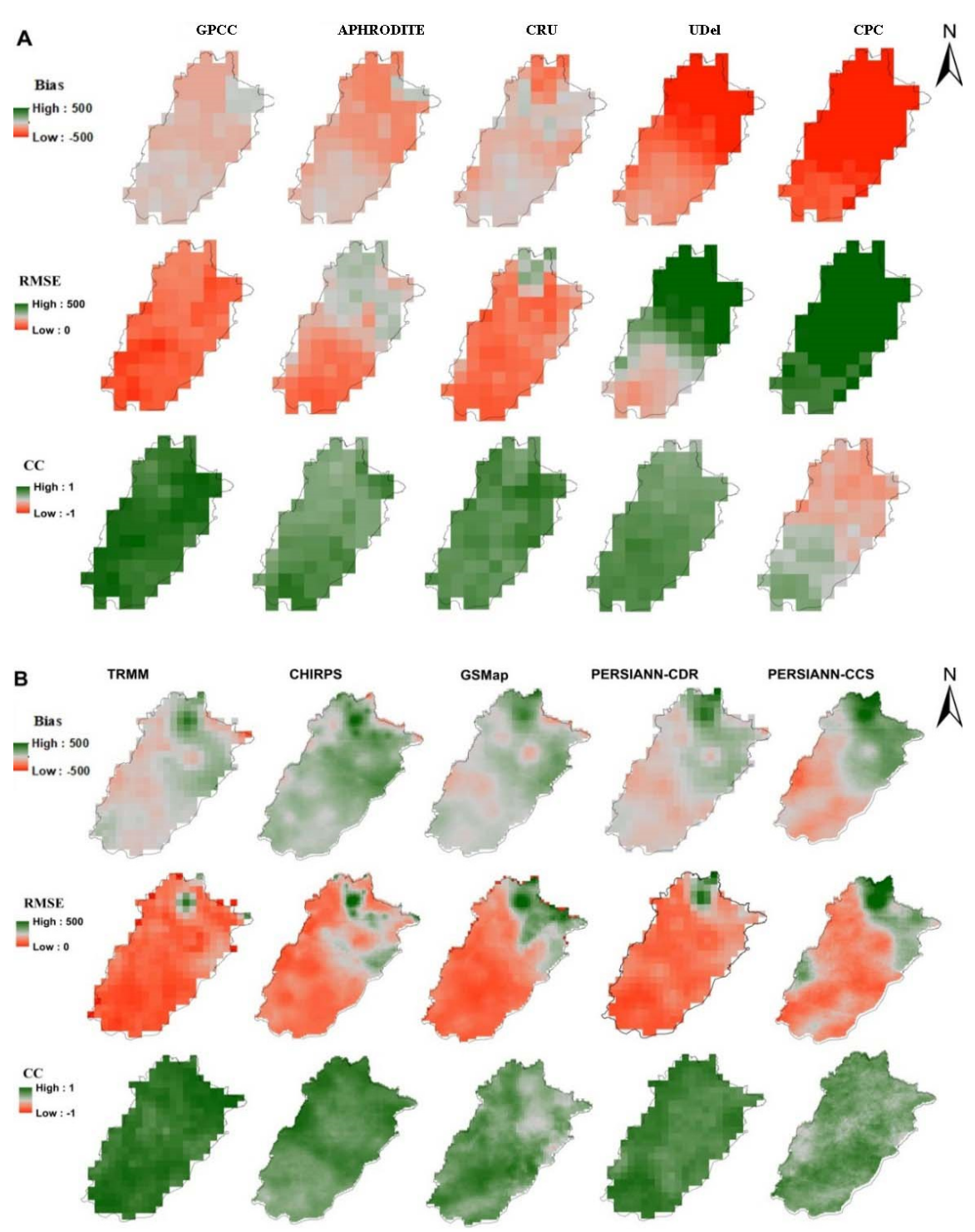

Figure 8. Spatial statistical indicators for the assessment of (A) (GB) and (B) (SB) precipitation products against reference data. 
Overall, the extent of under/over estimation of precipitation by GB and SB products suggests the significance of data correction before their reliable utilization in climate and hydrological studies. For the correction of precipitation products, we analyzed the estimated mean error in different data products and introduce a correction factor of each GB and SB product for annual, winter, and summer monsoon season over the Punjab region. The regional correction factor of each product for annual, winter, and summer monsoon during the period of 1979-2017 and 2003-2017 for GB and SB precipitation products are summarized in Table 2. The correction factor needs to be multiplied with the respective data products in order to minimize the percentage of error over the target region. The corrected product data could be directly used in climate modelling and other relevant studies [27].

Table 2. Annual and seasonal correction factors for each GPPs over Punjab region.

\begin{tabular}{cccc}
\hline GPPs & Annual & Winter-Monsoon & Summer-Monsoon \\
\hline CRU & 1.19 & 1.24 & 1.17 \\
GPCC & 1.18 & 1.31 & 1.15 \\
APHRODITE & 1.61 & 1.48 & 1.71 \\
CPC & 1.53 & 1.47 & 1.57 \\
UDel & 1.20 & 1.33 & 1.38 \\
TRMM & 0.99 & 0.84 & 1.06 \\
CHIRPS & 1.34 & 1.37 & 1.3 \\
GSMap & 1.05 & 0.61 & 2.33 \\
PERSIANN-CDR & 1.01 & 0.92 & 1.08 \\
PERSIANN-CCS & 1.01 & 0.72 & 1.79 \\
\hline
\end{tabular}

\subsection{Evaluation of Changing Trends and Abrupt Transition:}

Figure 9 presents the annual trends of precipitation products and observed data for Punjab region obtained by the MK and Theil-Sen approach. The trend plots are arranged as A and B with respect to GB and SB products during the study periods 1979-2017 and 2003-2017, respectively. The results indicated that, the annual observed precipitation revealed the insignificant positive trend during the periods 1979-2017 and 2003-2017 with the rate of 1.12 and $5.5 \mathrm{~mm} /$ decade, respectively. All of the GB and SB products exhibited the non-significant positive trend with the different scale of overestimation, except for CRU, CPC, and UDel products, which indicates the insignificant trend with the magnitude of $0.05,-1.38$, and $-0.06 \mathrm{~mm} /$ decade, respectively. These products are relatively less accurate to detect the observed precipitation trend. Though, GPCC and TRMM products outperformed other datasets in terms of trends magnitude with the rate of 1.29 and $5.53 \mathrm{~mm} /$ decade, which is quite close to the magnitude of observed precipitation. The range of overestimation was higher in SB products, which could be due to the shorter time period. The highest increasing trend was indicated by APHRODITE product followed by GSMap and PERSIANN products as compared with the observed precipitation trend. Overall, the performance of GPCC and TRMM precipitation products showed better agreement in terms of trend detection when compared with the observed precipitation. 


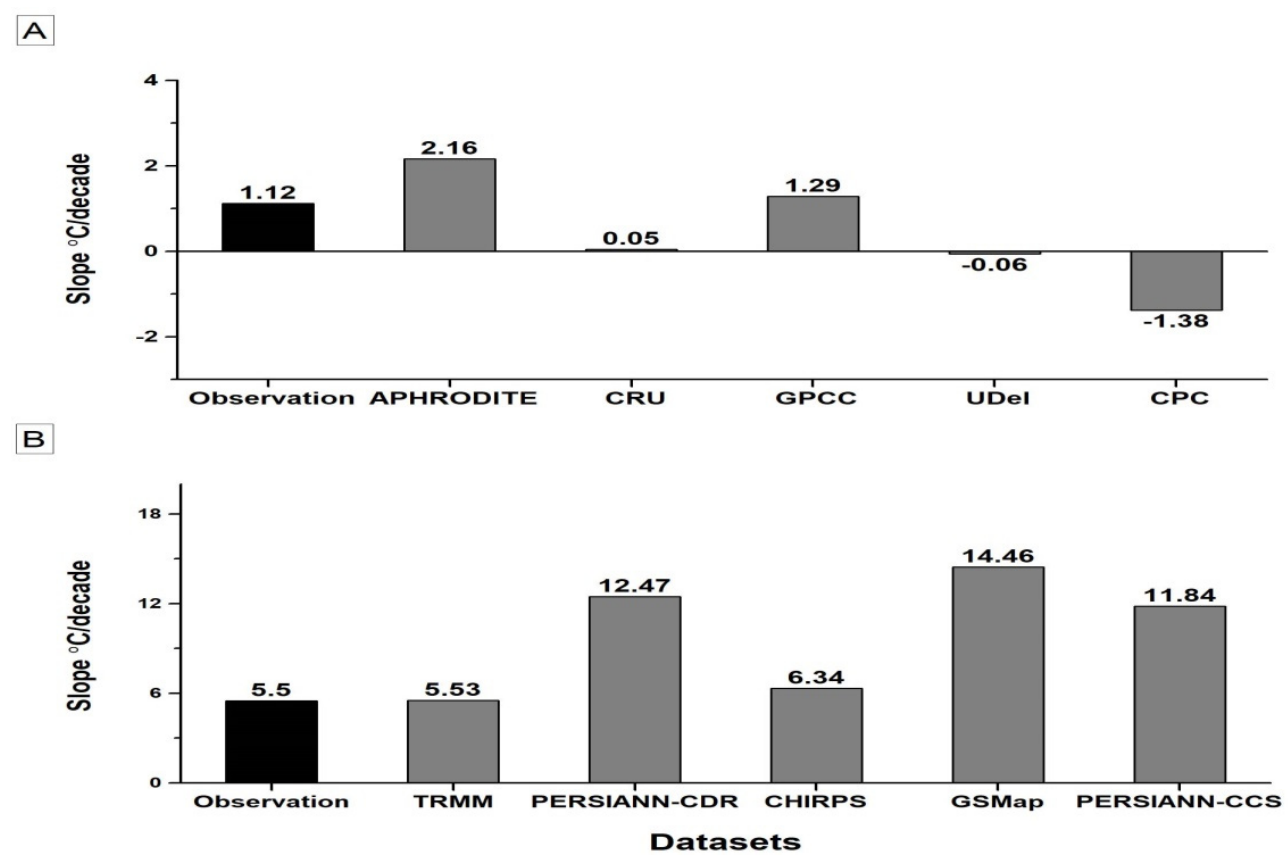

Figure 9. Comparative trend assessment of (A) (GB) and (B) (SB) precipitation products and reference data by using MK test (95\% confidence Interval).

The abrupt changes in climate data series revealed the transition of climate from one state to another due to some external factors, which activates a change to new state at a rate determined by the climate system [74,75]. The Sequential Mann-Kendall (SQMK) test was applied for the evaluation and comparison of different precipitation products with observed data over the Punjab region. The retrograde and progressive series were attained at 0.05 significance level. The comparative evaluation of GB and SB precipitation products with reference data using the SQMK test with the confidence interval of 95\% during the study periods 1979-2017 and 2003-2017 over the Punjab region are shown in Figure 10. The results indicate that the GPCC and TRMM products exhibited a similar pattern and mutation points as compared with reference data series. However, the other products also showed the similar fluctuated pattern in progressive series as compared with the reference data, yet they failed to capture the exact temporal mutation changes. The major fluctuations in the reference data series were detected during the period of 1984-1985 (negative), 1988-1989 (positive), 1998-1999 (negative), and 2005-2006 (positive). Moreover, the reference data showed the multiple turning points in progressive data series during the whole study Period. However, the gentle increase in the precipitation trend has been observed with no significant breakpoint during the period 2005-2017. All of the GB and SB products indicated the similar pattern of variability in progressive series. However, the TRMM product showed the best agreement as compared with the reference data series during this period over the Punjab region. The inter-annual and multi-decadal temporal abrupt changes in precipitation data series depicted a large fluctuation in precipitation over the targeted region during the whole study period. The major variabilities in the observed data series are well covenant with the findings of $[71,76]$, who reported the similar variability in precipitation over India and Pakistan, respectively. Overall, the GPCC and TRMM precipitation products outperformed the other products and revealed the best agreement when compared with reference data to capture the temporal pattern and mutation points in the precipitation data series over the target region. 

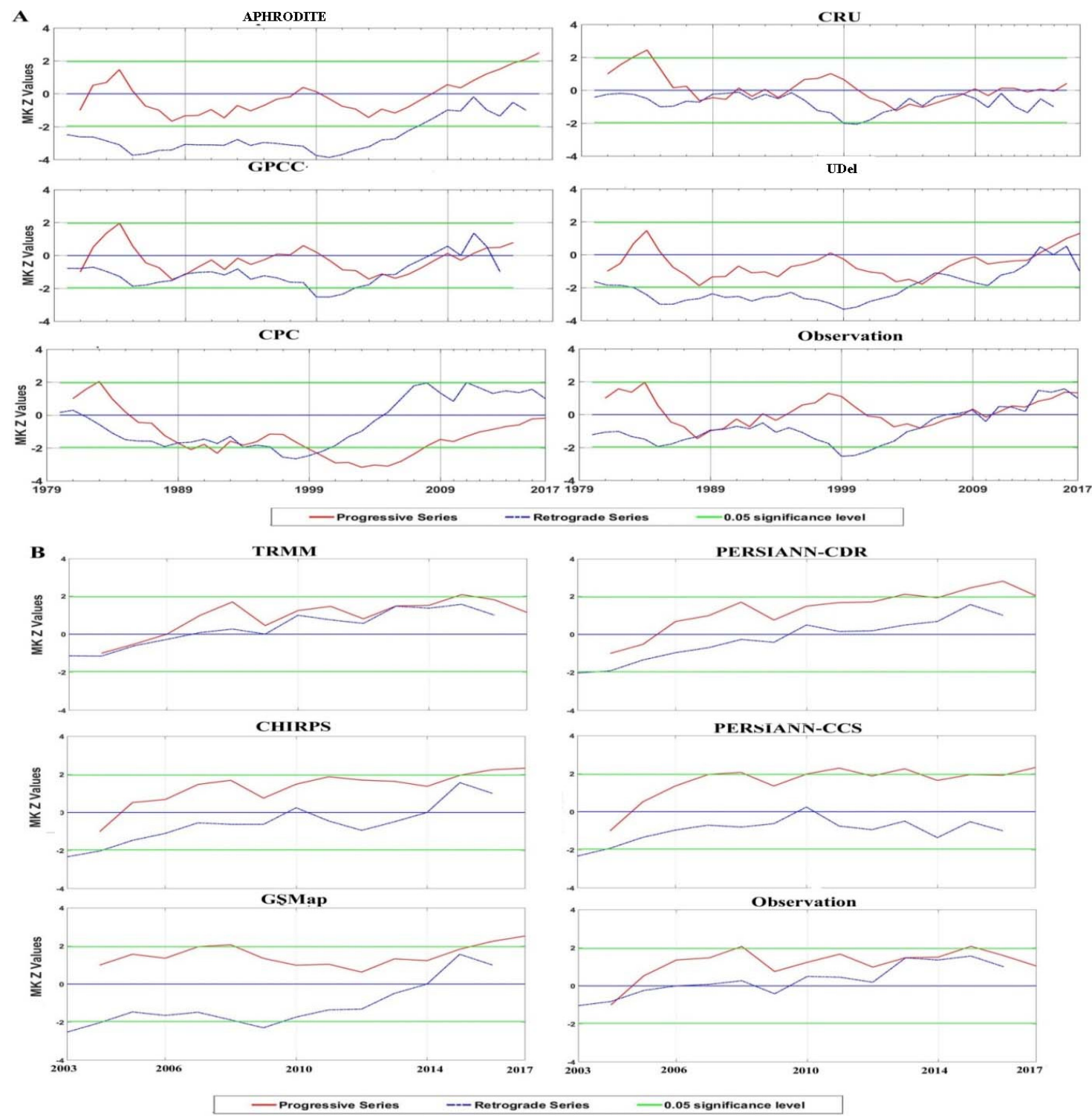

Figure 10. Comparison of Abrupt change detection in (A) (GB) and (B) (SB) precipitation products and reference data by using SQMK test (95\% confidence Interval).

\section{Discussion}

Spatial and temporal precipitation data acquisition is highly important for the regional climate studies as well as for the management of water resources and agriculture of the concerned regions. With the advancement in geo-information and remote sensing technologies, this paves the way to acquire gridded data free of cost on a different time and scale. However, the reliability and accuracy of the data must be quantified against the in-situ records at the regional scale [77]. The current study provides a comprehensive assessment of GB and SB precipitation products against the reference records over the Punjab province during annual, winter, and summer monsoon from the period of 1979-2017 and 2003-2017, respectively. Moreover, the changes in trends and detection of abrupt turning point in temporal data series of products were evaluated and compared with the reference data series. In addition, the correction factor for each product was introduced to minimize the percentage of error in the respective products.

The results indicate that the spatial and temporal performance of GPCC and TRMM precipitation product outperformed the other corresponding products in terms of statistical measurements (high value of CC and $\mathrm{R}^{2}$ with lower value of ME and RMSD) during the annual and summer monsoon season 
during 1979-2017 and 2003-2017, respectively. However, CRU performed better during winter estimates when compared with reference data during the whole study period. Moreover, the range of deviation among different precipitation products underestimated with different magnitude as compared with the reference data. We found large uncertainties in the magnitude and temporal variability among different products. The magnitude range of deviation was up 100-200 $\mathrm{mm}$ among different products within the same category and with reference data. The results of deviation are associated with the findings of [48], who reviewed the 22 global precipitation products and was reported the magnitude of deviation up to $300 \mathrm{~mm}$. All of the selected products estimated the higher amount of annual precipitation in the northern Punjab and exhibited the similar pattern from north to south gradient with the range of 1500-15 mm. However, the spatial deviation was more pronounced in the northern side as compared with the central and southern part of the study region. Moreover, the pattern of underestimation was more pronounced in the GB products as compared with SB products. One of the possible explanations of underestimation is due to lower pixel resolution of GB products over the study region [28].

Furthermore, the results showed that all of the GB products performed better in terms of lower values of ME during winter following by annual and summer monsoon season. However, the SB products showed better performance during annual scale following by summer and winter monsoon period. Overall, the agreement of GB products with observed precipitation decreases with the increase in the amount of precipitation and vice versa for SB precipitation products. The performance of SB precipitation products is well concomitant with the findings of $[28,78]$, who reported the better performance of SB products to capture the higher magnitude of precipitation and less accurate for low precipitation events over different regions of Pakistan. In contrast, [79] revealed the better performance of SB products with less rainfall events over northwest Himalaya regions. The extent of deviation in product similarity can possibly be attributed to multiple factors, which include difference in study region, elevation, land use and land cover change [28]. The pattern similarity by using Taylor diagram indicates the better performance of GPCC and TRMM products during annual and summer monsoon seasons in terms of higher CC of around 95\% during the whole study period. The results are well associated with the findings of [27], who reported the better pattern similarity performance of TRMM product in terms of higher CC of around $80 \%$ against other datasets during annual time scale over the upper Indus basin. The spatial distribution of statistical metrics (ME, RMSD, and CC) indicates the better performance of GPCC and TRMM products. However, the range of deviation in GB and SB products were more obvious in the northern Punjab with the overall pattern of underestimation (GB products) and overestimation (SB products) from the north to south gradient. The possible explanation of estimated deviation in GB and SB products over the northern Punjab could be due to wind induced errors and the presence of higher amount of aerosols in the atmosphere. The higher amount of aerosols in the atmosphere intercepts with the precipitation that reduces the efficiency of ground based meteorological stations [80]. Moreover, the wind induced errors can be attributed to the efficacy of ground based stations [81] Similarly, the pattern of overestimation in SB products particularly over northern Punjab could be associated with the higher rate of evaporation in the lower reaches of the mountains. These results are well associated with the findings of [82], who indicated the overestimation of SB products in the foothills of Himalaya mountain ranges over northern Pakistan. Moreover, the deviation in accuracy of GB products over northern Punjab could be due to inter-annual variability in weather, orographic effects and fewer gauges over the mountainous region. Many studies reported such effects in different climate studies over the northern belt of Pakistan $[27,28,79]$. Moreover, the fewer pixels of precipitation products also showed a weaker ability to capture the accurate spatial pattern in the central and southern parts of the study area. The possible explanation of accuracy deviation in these areas could be due the rapid extent of urban areas. Most of the meteorological station installed in the non-urban domain which could not represent the exact situation of climate variability in urban areas. Several studies documented the effect of urbanization on climate variability at a spatial scale [83]. 
The MK trends of observed precipitation indicate insignificant increasing trends during the period 1979-2017 and 2003-2017 with the rate of 1.12 and $5.5 \mathrm{~mm} /$ decade, respectively. The increasing trend was faster during period 2003-17 as compared with the period 1979-2017. The MK trend of GB and SB products showed the increasing trend with different magnitude of overestimation, except UDel and CPC products, which indicates decreasing trend as compared with observed precipitation. Furthermore, the abrupt transition analysis indicates the multiple turning points in precipitation data series during the period 1980-2005 with major abrupt changes in progressive series were detected during the period of 1984-1985 (negative), 1988-1989 (positive), 1998-1999 (negative), and 2005-2006 (positive). Many studies over the Asian and Indian monsoon system exhibited similar kind of precipitation trends over different timescales. [84-86]. The negative precipitation trend detected during the period of 1984-1985 and 1998-1999 could be due to major drought period over the whole country. The results are consistent with the findings of $[87,88]$, who reported the severe drought conditions in the country during the mid-80s and late 90s. Moreover, the gentle increase with no obvious break point has been detected in progressive data series during the period of 2005-2017. The large inter-annual variability in reference data series were well captured by GPCC and TRMM products during the period 1979-2017 and 2003-2017, respectively.

In spite of the fact that the spatial and temporal performance of GPCC and TRMM products outperformed the respective products in terms of lower values of ME, RMSD, and higher range of CC against in-situ records during the period 1979-2017 and 2003-2017, respectively. However, it is still uncertain to estimate the accurate amount of precipitation, as witnessed by the estimated mean error in the precipitation products over the whole study region. In view of significant extent of biases in the products, we determined the factor of correction of each product for their reliable utilization in hydro-climate projects on annual, winter, and summer monsoon periods over the Punjab region. The results of estimated correction factors of different precipitation products are well covenant with the findings of $[27,89]$, who estimated the adjustment factors of precipitation products for Upper Indus Basin (UIB). However, the magnitude of the estimated correction factors is different due to different study period and region.

The spatial and temporal performance of the products depend on a multiple factors, which are intricate in the data algorithms of the products, e.g., sources of data, spatial and temporal resolution, interpolation techniques, missing gaps in data and topography, etc. [50,90]. Similarly, the number of stations, quality, and time scale of in-situ records used for the evaluation of global products are also very important for the identification of potential product for the specific regions [72]. The detection of autocorrelation in the datasets is also important for the accuracy of trends detection and abrupt changes in the climate data series. However, the presence of autocorrelation was more significant for precipitation products, particularly for high altitude regions above $4000 \mathrm{~m}$ [27]. The superior performance of GPCC and TRMM precipitation products over the Punjab region might be due to their better data processing procedures, number of gauge station into account, and interpolation techniques.

The precipitation products, even with their intrinsic biases and limitations, are still important for providing valuable source of information related to precipitation variability on spatial and temporal scale. The global precipitation products are also important for climate studies when there is a lack of funding or resources to go into the field and record these types of observations. Caution must also be exercised when comparing and using the GPPs; large uncertainty exists where gauge density is low [91]. The present study highlights the potential products for precipitation over the Punjab province. The evaluation results are beneficial for improving our understanding towards the use of products in arid and semi-arid regions, like Punjab province. However, the spatial and temporal discrepancies were also identified, which will be useful for the further use of these products in hydro-meteorological applications. In view of large discrepancies among the products, future studies should focus on the new methods for the better comparative accuracy and evaluation procedure of global climate products. For instance, [92] introduce a new method of evaluation and decision making by using the fuzzy logic procedure based on the integrated linguistic operated weighted average (ILOWA) method. The main 
advantage of this technique is to provide sustainable products by using different linguistic terms that are primarily an easy approach for decision making. The products assessments based on integrated models could increase the level of accuracy for the appropriate selection of potential products by considering the statistical indicators.

\section{Conclusions}

In this study, the gridded precipitation products (GB and SB products) were evaluated against the reference data during 1979-2017 and 2003-2017 periods on annual, winter, and summer monsoon scale by using multiple statistical methods in order to gain an understanding for the potential of Gauge and satellite based precipitation products over the Punjab province, Pakistan. The major outcomes of the study can be summarized as follows.

The result indicated that the temporal magnitude in all of the precipitation products was different and deviated up to 100-200 mm with overall spatial pattern of underestimation (GB products) and overestimation (SB products) from north to south gradient as compared with in-situ measurements. Though, the GPCC and TRMM products outperformed the relative GPPs and showed the best agreement against the reference data in terms of higher $R^{2}$ values of $\geq 0.90$ and lower values of estimated RME $\leq 25 \%$ at annual and summer monsoon seasons. However, CRU performed better during winter monsoon season with the estimated ME of $-25.08(-20.49 \%)$ and R-squared value of 0.91 as compared with the reference data during the period 1979-2017. All of the GB products performed better in terms of lower values of estimated ME during winter following by annual and summer monsoon season. However, SB products showed better performance during annual scale following by summer and winter monsoon period. Overall, the degree of accuracy of GB products with observed precipitation decreases with the increase in the magnitude of precipitation and vice versa for SB precipitation products

The Mann-Kendall results indicated that, the annual observed precipitation revealed the insignificant positive trend during the periods 1979-2017 and 2003-2017 with the rate of 1.12 and $5.5 \mathrm{~mm} /$ decade, respectively. However, the abrupt transition analysis indicates the multiple turning points in the reference data series during the period 1980-2005 with major abrupt changes were detected during the period of 1984-1985 (negative), 1988-1989 (positive), 1998-1999 (negative), and 2005-2006 (positive). The large inter-annual variability in the reference data series were well captured by GPCC and TRMM products during the period 1979-2017 and 2003-2017, respectively. In view of significant extent of biases in the GPPs, the estimated correction factor during annual, winter and summer monsoon seasons for each GPP can be useful for future hydro-climate projects over the Punjab region. The range of discrepancies in precipitation products pointed out the further improvement of GPPs for the enhancement of its accuracy over the arid and semi-arid regions, like Punjab Province. Moreover, the degree of accuracy in precipitation products varies with time and resolution; therefore, products should be assessed at different spatio-temporal scale.

Author Contributions: X.L. and Y.C. designed and supervised this study. Z.N. carried out the research and wrote the manuscript. N.N. and R.G. assisted in formatting and editing the manuscript. A.E. helped in data processing and analysis. All authors have read and agreed to the published version of the manuscript.

Funding: This study is supported by the Strategic Priority Research Program of the Chinese Academy of Sciences, Grant No. XDA20100104, and the National Natural Science Foundation of China through Grant No. 41871280.

Acknowledgments: The authors acknowledge the climate agencies efforts for providing the GPPs datasets. We also used in-situ data from the Pakistan Meteorological Department (PMD). The authors cordially appreciate the PMD, whose efforts made it possible for us to access the data. We also recognize the support of the CAS-TWAS president fellowship program for PhD.

Conflicts of Interest: The authors declare no conflict of interest. 


\section{References}

1. Nawaz, Z.; Li, X.; Chen, Y.; Guo, Y.; Wang, X.; Nawaz, N. Temporal and spatial characteristics of precipitation and temperature in Punjab, Pakistan. Water 2019, 11, 1916. [CrossRef]

2. Jain, S.K.; Kumar, V.; Saharia, M. Analysis of rainfall and temperature trends in northeast India. Int. J. Climatol. 2013, 33, 968-978. [CrossRef]

3. Beck, H.E.; Pan, M.; Roy, T.; Weedon, G.P.; Pappenberger, F.; van Dijk, A.I.J.M.; Huffman, G.J.; Adler, R.F.; Wood, E.F. Daily evaluation of 26 precipitation datasets using Stage-IV gauge-radar data for the CONUS. Hydrol. Earth Syst. Sci. 2019, 23, 207-224. [CrossRef]

4. Hamdi, M.R.; Abu-Allaban, M.; Elshaieb, A.; Jaber, M.; Momani, N.M. Climate change in Jordan: A comprehensive examination approach. Am. J. Environ. Sci. 2009, 5, 740-750. [CrossRef]

5. Matti, C.; Pauling, A.; Küttel, M.; Wanner, H. Winter precipitation trends for two selected European regions over the last 500 years and their possible dynamical background. Theor. Appl. Climatol. 2009, 95, 9-26. [CrossRef]

6. Singh, P.; Kumar, V.; Thomas, T.; Arora, M. Basin-wide assessment of temperature trends in northwest and central India/Estimation par bassin versant de tendances de température au nord-ouest et au centre de l'Inde. Hydrol. Sci. J. 2008, 53, 421-433. [CrossRef]

7. De la Casa, A.; Nasello, O. Breakpoints in annual rainfall trends in Córdoba, Argentina. Atmos. Res. 2010, 95, 419-427. [CrossRef]

8. Gleick, P.H. Climate change, hydrology, and water resources. Rev. Geophys. 1989, 27, 329-344. [CrossRef]

9. Feng, S.; Hu, Q.; Qian, W. Quality control of daily meteorological data in China, 1951-2000: A new dataset. Int. J. Climatol. A J. R. Meteorol. Soc. 2004, 24, 853-870. [CrossRef]

10. Jiang, S.; Ren, L.; Hong, Y.; Yong, B.; Yang, X.; Yuan, F.; Ma, M. Comprehensive evaluation of multi-satellite precipitation products with a dense rain gauge network and optimally merging their simulated hydrological flows using the Bayesian model averaging method. J. Hydrol. 2012, 452, 213-225. [CrossRef]

11. Liu, X.; Yang, T.; Hsu, K.; Liu, C.; Sorooshian, S. Evaluating the streamflow simulation capability of PERSIANN-CDR daily rainfall products in two river basins on the Tibetan Plateau. Hydrol. Earth Syst. Sci. 2017, 21, 169-181. [CrossRef]

12. Tapiador, F.J.; Turk, F.J.; Petersen, W.; Hou, A.Y.; García-Ortega, E.; Machado, L.A.T.; Angelis, C.F.; Salio, P.; Kidd, C.; Huffman, G.J. Global precipitation measurement: Methods, datasets and applications. Atmos. Res. 2012, 104, 70-97. [CrossRef]

13. Wang, W.; Lu, H.; Zhao, T.; Jiang, L.; Shi, J. Evaluation and comparison of daily rainfall from latest GPM and TRMM products over the Mekong River Basin. IEEE J. Sel. Top. Appl. Earth Obs. Remote Sens. 2017, 10, 2540-2549. [CrossRef]

14. Nashwan, M.; Shahid, S.; Chung, E.-S.; Ahmed, K.; Song, Y. Development of climate-based index for hydrologic hazard susceptibility. Sustainability 2018, 10, 2182. [CrossRef]

15. Albright, T.P.; Pidgeon, A.M.; Rittenhouse, C.D.; Clayton, M.K.; Wardlow, B.D.; Flather, C.H.; Culbert, P.D.; Radeloff, V.C. Combined effects of heat waves and droughts on avian communities across the conterminous United States. Ecosphere 2010, 1, 1-22. [CrossRef]

16. Nkiaka, E.; Nawaz, N.R.; Lovett, J.C. Evaluating global reanalysis precipitation datasets with rain gauge measurements in the Sudano-Sahel region: Case study of the Logone catchment, Lake Chad Basin. Meteorol. Appl. 2017, 24, 9-18. [CrossRef]

17. Zhao, Y.; Xie, Q.; Lu, Y.; Hu, B. Hydrologic evaluation of TRMM multisatellite precipitation analysis for Nanliu river basin in Humid Southwestern China. Sci. Rep. 2017, 7, 2470. [CrossRef]

18. Kunkel, K.E.; Vose, R.S.; Stevens, L.E.; Knight, R.W. Is the monthly temperature climate of the United States becoming more extreme? Geophys. Res. Lett. 2015, 42, 629-636. [CrossRef]

19. Kunkel, K.E.; Andsager, K.; Easterling, D.R. Long-term trends in extreme precipitation events over the conterminous United States and Canada. J. Clim. 1999, 12, 2515-2527. [CrossRef]

20. Rajah, K.; O'Leary, T.; Turner, A.; Petrakis, G.; Leonard, M.; Westra, S. Changes to the temporal distribution of daily precipitation. Geophys. Res. Lett. 2014, 41, 8887-8894. [CrossRef]

21. Daly, C.; Slater, M.E.; Roberti, J.A.; Laseter, S.H.; Swift, L.W., Jr. High-resolution precipitation mapping in a mountainous watershed: Ground truth for evaluating uncertainty in a national precipitation dataset. Int. J. Climatol. 2017, 37, 124-137. [CrossRef] 
22. Hunziker, S.; Gubler, S.; Calle, J.; Moreno, I.; Andrade, M.; Velarde, F.; Ticona, L.; Carrasco, G.; Castellón, Y.; Oria, C. Identifying, attributing, and overcoming common data quality issues of manned station observations. Int. J. Climatol. 2017, 37, 4131-4145. [CrossRef]

23. Khairul, I.; Mastrantonas, N.; Rasmy, M.; Koike, T.; Takeuchi, K. Inter-comparison of gauge-corrected global satellite rainfall estimates and their applicability for effective water resource management in a transboundary river basin: The case of the Meghna River basin. Remote Sens. 2018, 10, 828. [CrossRef]

24. Samadi, S.; Carbone, G.J.; Mahdavi, M.; Sharifi, F.; Bihamta, M.R. Statistical downscaling of climate data to estimate streamflow in a semi-arid catchment. Hydrol. Earth Syst. Sci. Discuss. 2012, 9, 4869-4918. [CrossRef]

25. Buytaert, W.; Friesen, J.; Liebe, J.; Ludwig, R. Assessment and management of water resources in developing, semi-arid and arid regions. Water Resour. Manag. 2012, 26, 841-844. [CrossRef]

26. Ahmad, W.; Fatima, A.; Awan, U.K.; Anwar, A. Analysis of long term meteorological trends in the middle and lower Indus Basin of Pakistan-A non-parametric statistical approach. Glob. Planet. Chang. 2014, 122, 282-291. [CrossRef]

27. Dahri, Z.H.; Ludwig, F.; Moors, E.; Ahmad, B.; Khan, A.; Kabat, P. An appraisal of precipitation distribution in the high-altitude catchments of the Indus basin. Sci. Total Environ. 2016, 548, 289-306. [CrossRef]

28. Ullah, W.; Wang, G.; Ali, G.; Tawia Hagan, D.F.; Bhatti, A.S.; Lou, D. Comparing multiple precipitation products against in-situ observations over different climate regions of Pakistan. Remote Sens. 2019, 11, 628. [CrossRef]

29. Krakauer, N.Y.; Lakhankar, T.; Dars, G.H. Precipitation trends over the Indus basin. Climate 2019, 7, 116. [CrossRef]

30. Iqbal, M.F.; Athar, H. Validation of satellite based precipitation over diverse topography of Pakistan. Atmos. Res. 2018, 201, 247-260. [CrossRef]

31. Khattak, M.S.; Reman, N.U.; Sharif, M.; Khan, M.A. Analysis of streamflow data for trend detection on major rivers of the Indus Basin. J. Himal. Earth Sci. 2015, 48, 87.

32. Ashiq, M.W.; Zhao, C.; Ni, J.; Akhtar, M. GIS-based high-resolution spatial interpolation of precipitation in mountain-plain areas of Upper Pakistan for regional climate change impact studies. Theor. Appl. Climatol. 2010, 99, 239. [CrossRef]

33. Abbas, F. Analysis of a historical (1981-2010) temperature record of the Punjab province of Pakistan. Earth Interact. 2013, 17, 1-23. [CrossRef]

34. Khan, S.U.; Hasan, M.U.; Khan, F.K.; Bari, A. Climate classification of Pakistan. In Proceedings of the Fourth International Scientific Conference BALWOIS 2010, Ohrid, North Macedonia, 25-29 May 2010.

35. Asmat, U.; Athar, H.; Nabeel, A.; Latif, M. An AOGCM based assessment of interseasonal variability in Pakistan. Clim. Dyn. 2018, 50, 349-373. [CrossRef]

36. Nawaz, Z.; Li, X.; Chen, Y.; Wang, X.; Zhang, K.; Nawaz, N.; Guo, Y.; Meerzhan, A. Spatiotemporal assessment of temperature data products for the detection of warming trends and abrupt transitions over the largest irrigated area of Pakistan. Adv. Meteorol. 2020, 2020, 3584030. [CrossRef]

37. Chen, Y.; Ebert, E.E.; Walsh, K.J.E.; Davidson, N.E. Evaluation of TRMM 3B42 precipitation estimates of tropical cyclone rainfall using PACRAIN data. J. Geophys. Res. Atmos. 2013, 118, 2184-2196. [CrossRef]

38. Habib, E.; Henschke, A.; Adler, R.F. Evaluation of TMPA satellite-based research and real-time rainfall estimates during six tropical-related heavy rainfall events over Louisiana, USA. Atmos. Res. 2009, 94, 373-388. [CrossRef]

39. Iqbal, M.; Wen, J.; Wang, X.; Lan, Y.; Tian, H.; Anjum, M.N.; Adnan, M. Assessment of air temperature trends in the source Region of Yellow River and its sub-basins. Asia Pac. J. Atmos. Sci. 2018, 54, 111-123. [CrossRef]

40. Mitchell, J.M.; Dzerdzeevskii, B.; Flohn, H.; Hofmeyr, W.L.; Lamb, H.H.; Rao, K.N.; Wallén, C.C. Climatic Change; Technical Note, No. 79; World Meteorological Organization: Geneva, Switzerland, 1966; Volume 99.

41. Peterson, T.C.; Easterling, D.R.; Karl, T.R.; Groisman, P.; Nicholls, N.; Plummer, N.; Torok, S.; Auer, I.; Boehm, R.; Gullett, D. Homogeneity adjustments of in situ atmospheric climate data: A review. Int. J. Climatol. A J. R. Meteorol. Soc. 1998, 18, 1493-1517. [CrossRef]

42. Kohler, M.A. On the Use of Double-Mass Analysis for Testing the Consistency of Meteorological Records and for Making Required Adjustments. Bull. Am. Meteorol. Soc. J. 1949, 30, 188-195. [CrossRef]

43. Craven, P.; Wahba, G. Smoothing noisy data with spline functions. Numer. Math. 1978, 31, $377-403$. [CrossRef] 
44. Hutchinson, M.F.; Gessler, P.E. Splines-More than just a smooth interpolator. Geoderma 1994, 62, 45-67. [CrossRef]

45. Partal, T. Wavelet transform-based analysis of periodicities and trends of Sakarya basin (Turkey) streamflow data. River Res. Appl. 2010, 26, 695-711. [CrossRef]

46. Sonali, P.; Kumar, D.N. Review of trend detection methods and their application to detect temperature changes in India. J. Hydrol. 2013, 476, 212-227. [CrossRef]

47. Sayemuzzaman, M.; Jha, M.K. Seasonal and annual precipitation time series trend analysis in North Carolina, United States. Atmos. Res. 2014, 137, 183-194. [CrossRef]

48. Sun, Q.; Miao, C.; Duan, Q.; Ashouri, H.; Sorooshian, S.; Hsu, K. A review of global precipitation data sets: Data sources, estimation, and intercomparisons. Rev. Geophys. 2018, 56, 79-107. [CrossRef]

49. Willmott, C.J.; Matsuura, K. Smart interpolation of annually averaged air temperature in the United States. J. Appl. Meteorol. 1995, 34, 2577-2586. [CrossRef]

50. Harris, I.; Jones, P.D.; Osborn, T.J.; Lister, D.H. Updated high-resolution grids of monthly climatic observations-the CRU TS3. 10 Dataset. Int. J. Climatol. 2014, 34, 623-642. [CrossRef]

51. Yatagai, A.; Kamiguchi, K.; Arakawa, O.; Hamada, A.; Yasutomi, N.; Kitoh, A. Aphrodite constructing a long-term daily gridded precipitation dataset for Asia based on a dense network of rain gauges. Bull. Am. Meteorol. Soc. 2012, 93, 1401-1415. [CrossRef]

52. Xie, P.; Chen, M.; Shi, W. CPC unified gauge-based analysis of global daily precipitation. In Proceedings of the 24th Conference on Hydrology, Atlanta, GA, USA, 16-21 January 2010.

53. Huffman, G.J.; Bolvin, D.T.; Nelkin, E.J.; Wolff, D.B.; Adler, R.F.; Gu, G.; Hong, Y.; Bowman, K.P.; Stocker, E.F. The TRMM multisatellite precipitation analysis (TMPA): Quasi-global, multiyear, combined-sensor precipitation estimates at fine scales. J. Hydrometeorol. 2007, 8, 38-55. [CrossRef]

54. Li, W.; Sun, W.; He, X.; Scaioni, M.; Yao, D.; Chen, Y.; Gao, J.; Li, X.; Cheng, G. Improving CHIRPS daily satellite-precipitation products using coarser ground observations. IEEE Geosci. Remote Sens. Lett. 2019, 16, 1678-1682. [CrossRef]

55. Ashouri, H.; Hsu, K.-L.; Sorooshian, S.; Braithwaite, D.K.; Knapp, K.R.; Cecil, L.D.; Nelson, B.R.; Prat, O.P. PERSIANN-CDR: Daily precipitation climate data record from multisatellite observations for hydrological and climate studies. Bull. Am. Meteorol. Soc. 2015, 96, 69-83. [CrossRef]

56. Adler, R.F.; Huffman, G.J.; Chang, A.; Ferraro, R.; Xie, P.-P.; Janowiak, J.; Rudolf, B.; Schneider, U.; Curtis, S.; Bolvin, D. The version-2 global precipitation climatology project (GPCP) monthly precipitation analysis (1979-present). J. Hydrometeorol. 2003, 4, 1147-1167. [CrossRef]

57. Hong, Y.; Gochis, D.; Cheng, J.; Hsu, K.; Sorooshian, S. Evaluation of PERSIANN-CCS rainfall measurement using the NAME event rain gauge network. J. Hydrometeorol. 2007, 8, 469-482. [CrossRef]

58. Funk, C.; Peterson, P.; Landsfeld, M.; Pedreros, D.; Verdin, J.; Shukla, S.; Husak, G.; Rowland, J.; Harrison, L.; Hoell, A. The climate hazards infrared precipitation with stations-A new environmental record for monitoring extremes. Sci. Data 2015, 2,1-21. [CrossRef]

59. Ushio, T.; Sasashige, K.; Kubota, T.; Shige, S.; Okamoto, K.; Aonashi, K.; Inoue, T.; Takahashi, N.; Iguchi, T.; Kachi, M. A Kalman filter approach to the Global Satellite Mapping of Precipitation (GSMaP) from combined passive microwave and infrared radiometric data. J. Meteorol. Soc. Japan. Ser. II 2009, 87, 137-151. [CrossRef]

60. Taylor, K.E. Summarizing multiple aspects of model performance in a single diagram. J. Geophys. Res. Atmos. 2001, 106, 7183-7192. [CrossRef]

61. Chen, Y.; Guan, Y.; Shao, G.; Zhang, D. Investigating trends in streamflow and precipitation in Huangfuchuan Basin with wavelet analysis and the Mann-Kendall test. Water 2016, 8, 77. [CrossRef]

62. Yang, P.; Xia, J.; Zhang, Y.; Hong, S. Temporal and spatial variations of precipitation in Northwest China during 1960-2013. Atmos. Res. 2017, 183, 283-295. [CrossRef]

63. Zamani, R.; Mirabbasi, R.; Abdollahi, S.; Jhajharia, D. Streamflow trend analysis by considering autocorrelation structure, long-term persistence, and Hurst coefficient in a semi-arid region of Iran. Theor. Appl. Climatol. 2017, 129, 33-45. [CrossRef]

64. Sen, P.K. Estimates of the regression coefficient based on Kendall's tau. J. Am. Stat. Assoc. 1968, 63, 1379-1389. [CrossRef]

65. Zhang, X.; Zwiers, F.W.; Li, G. Monte Carlo experiments on the detection of trends in extreme values. J. Clim. 2004, 17, 1945-1952. [CrossRef] 
66. Sneyers, R. On the Statistical Analysis of Series of Observations; World Meteorological Organization: Geneva, Switzerland, 1990; ISBN 9263104158.

67. Zarenistanak, M.; Dhorde, A.G.; Kripalani, R.H. Trend analysis and change point detection of annual and seasonal precipitation and temperature series over southwest Iran. J. Earth Syst. Sci. 2014, 123, 281-295. [CrossRef]

68. Mann, H.B. Non-parametric tests against trend. Econmetrica 1945, 13, 245-259. [CrossRef]

69. Mantua, N.J.; Hare, S.R.; Zhang, Y.; Wallace, J.M.; Francis, R.C. A Pacific interdecadal climate oscillation with impacts on salmon production. Bull. Amer. Meteor. Soc. 1997, 78, 1069-1080. [CrossRef]

70. Kendall, M.G. Rank Correlation Measures; Charles Griffin: London, UK, 1975; Volume 202, p. 15.

71. Ullah, S.; You, Q.; Ullah, W.; Ali, A. Observed changes in precipitation in China-Pakistan economic corridor during 1980-2016. Atmos. Res. 2018, 210, 1-14. [CrossRef]

72. Ahmed, K.; Shahid, S.; Wang, X.; Nawaz, N.; Khan, N. Evaluation of gridded precipitation datasets over arid regions of Pakistan. Water 2019, 11, 210. [CrossRef]

73. Khan, S.I.; Hong, Y.; Gourley, J.J.; Khattak, M.U.K.; Yong, B.; Vergara, H.J. Evaluation of three high-resolution satellite precipitation estimates: Potential for monsoon monitoring over Pakistan. Adv. Sp. Res. 2014, 54, 670-684. [CrossRef]

74. Xu, M.; Kang, S.; Wu, H.; Yuan, X. Detection of spatio-temporal variability of air temperature and precipitation based on long-term meteorological station observations over Tianshan Mountains, Central Asia. Atmos. Res. 2018, 203, 141-163. [CrossRef]

75. Rashid, M.M.; Beecham, S.; Chowdhury, R.K. Assessment of trends in point rainfall using continuous wavelet transforms. Adv. Water Resour. 2015, 82, 1-15. [CrossRef]

76. Priya, P.; Mujumdar, M.; Sabin, T.P.; Terray, P.; Krishnan, R. Impacts of Indo-Pacific sea surface temperature anomalies on the summer monsoon circulation and heavy precipitation over northwest India-Pakistan region during 2010. J. Clim. 2015, 28, 3714-3730. [CrossRef]

77. Gampe, D.; Ludwig, R. Evaluation of gridded precipitation data products for hydrological applications in complex topography. Hydrology 2017, 4, 53. [CrossRef]

78. Naveed, M.; Ding, Y.; Shangguan, D.; Ahmad, I. Performance evaluation of latest integrated multi-satellite retrievals for Global Precipitation Measurement (IMERG) over the northern highlands of Pakistan. Atmos. Res. 2018, 205, 134-146.

79. Bharti, V.; Singh, C. Evaluation of error in TRMM 3B42V7 precipitation estimates over the Himalayan region. J. Geophys. Res. Atmos. 2015, 120, 12458-12473. [CrossRef]

80. Kaufman, Y.J.; Tanré, D.; Boucher, O. A satellite view of aerosols in the climate system. Nature 2002, 419, 215-223. [CrossRef] [PubMed]

81. Tahir, A.A.; Adamowski, J.F.; Chevallier, P.; Haq, A.U.; Terzago, S. Comparative assessment of spatiotemporal snow cover changes and hydrological behavior of the Gilgit, Astore and Hunza River basins (Hindukush-Karakoram-Himalaya region, Pakistan). Meteorol. Atmos. Phys. 2016, 128, 793-811. [CrossRef]

82. Palazzi, E.; von Hardenberg, J.; Provenzale, A. Precipitation in the Hindu-Kush Karakoram Himalaya: Observations and future scenarios. J. Geophys. Res. Atmos. 2013, 118, 85-100. [CrossRef]

83. Ren, G.; Zhou, Y. Urbanization effect on trends of extreme temperature indices of national stations over Mainland China, 1961-2008. J. Clim. 2014, 27, 2340-2360. [CrossRef]

84. Kripalani, R.H.; Oh, J.H.; Kulkarni, A.; Sabade, S.S.; Chaudhari, H.S. South Asian summer monsoon precipitation variability: Coupled climate model simulations and projections under IPCC AR4. Theor. Appl. Climatol. 2007, 90, 133-159. [CrossRef]

85. Latif, M.; Syed, F.S.; Hannachi, A. Rainfall trends in the South Asian summer monsoon and its related large-scale dynamics with focus over Pakistan. Clim. Dyn. 2017, 48, 3565-3581. [CrossRef]

86. Wang, P.X.; Wang, B.; Cheng, H.; Fasullo, J.; Guo, Z.; Kiefer, T.; Liu, Z. The global monsoon across time scales: Mechanisms and outstanding issues. Earth Sci. Rev. 2017, 174, 84-121. [CrossRef]

87. Xie, H.; Ringler, C.; Zhu, T.; Waqas, A. Droughts in Pakistan: A spatiotemporal variability analysis using the Standardized Precipitation Index. Water Int. 2013, 38, 620-631. [CrossRef]

88. Jamro, S.; Dars, G.H.; Ansari, K.; Krakauer, N.Y. Spatio-temporal variability of drought in Pakistan using standardized precipitation evapotranspiration index. Appl. Sci. 2019, 9, 4588. [CrossRef] 
89. Lutz, A.F.; Immerzeel, W.W.; Shrestha, A.B.; Bierkens, M.F.P. Consistent increase in High Asia's runoff due to increasing glacier melt and precipitation. Nat. Clim. Chang. 2014, 4, 587-592. [CrossRef]

90. Fu, G.; Yu, J.; Yu, X.; Ouyang, R.; Zhang, Y.; Wang, P.; Liu, W.; Min, L. Temporal variation of extreme rainfall events in China, 1961-2009. J. Hydrol. 2013, 487, 48-59. [CrossRef]

91. McEvoy, D.J.; Mejia, J.F.; Huntington, J.L. Use of an observation network in the Great Basin to evaluate gridded climate data. J. Hydrometeorol. 2014, 15, 1913-1931. [CrossRef]

92. Rodger, J.A.; George, J.A. Triple bottom line accounting for optimizing natural gas sustainability: A statistical linear programming fuzzy ILOWA optimized sustainment model approach to reducing supply chain global cybersecurity vulnerability through information and communications t. J. Clean. Prod. 2017, 142, 1931-1949. [CrossRef]

Publisher's Note: MDPI stays neutral with regard to jurisdictional claims in published maps and institutional affiliations.

(C) 2020 by the authors. Licensee MDPI, Basel, Switzerland. This article is an open access article distributed under the terms and conditions of the Creative Commons Attribution (CC BY) license (http://creativecommons.org/licenses/by/4.0/). 